\title{
Política educacional: un estudo comparativo sobpe os impactos de um novo modelo pedagógico
}

Aline Maria de Medeiros

Rodrigues Reali

Vicente Manuel

Cristofoletti Calvo

Palavras-chave: indicadores educacionais; avaliação de sistemas educacionais; corpo discente; políticas públicas.

\author{
:
}

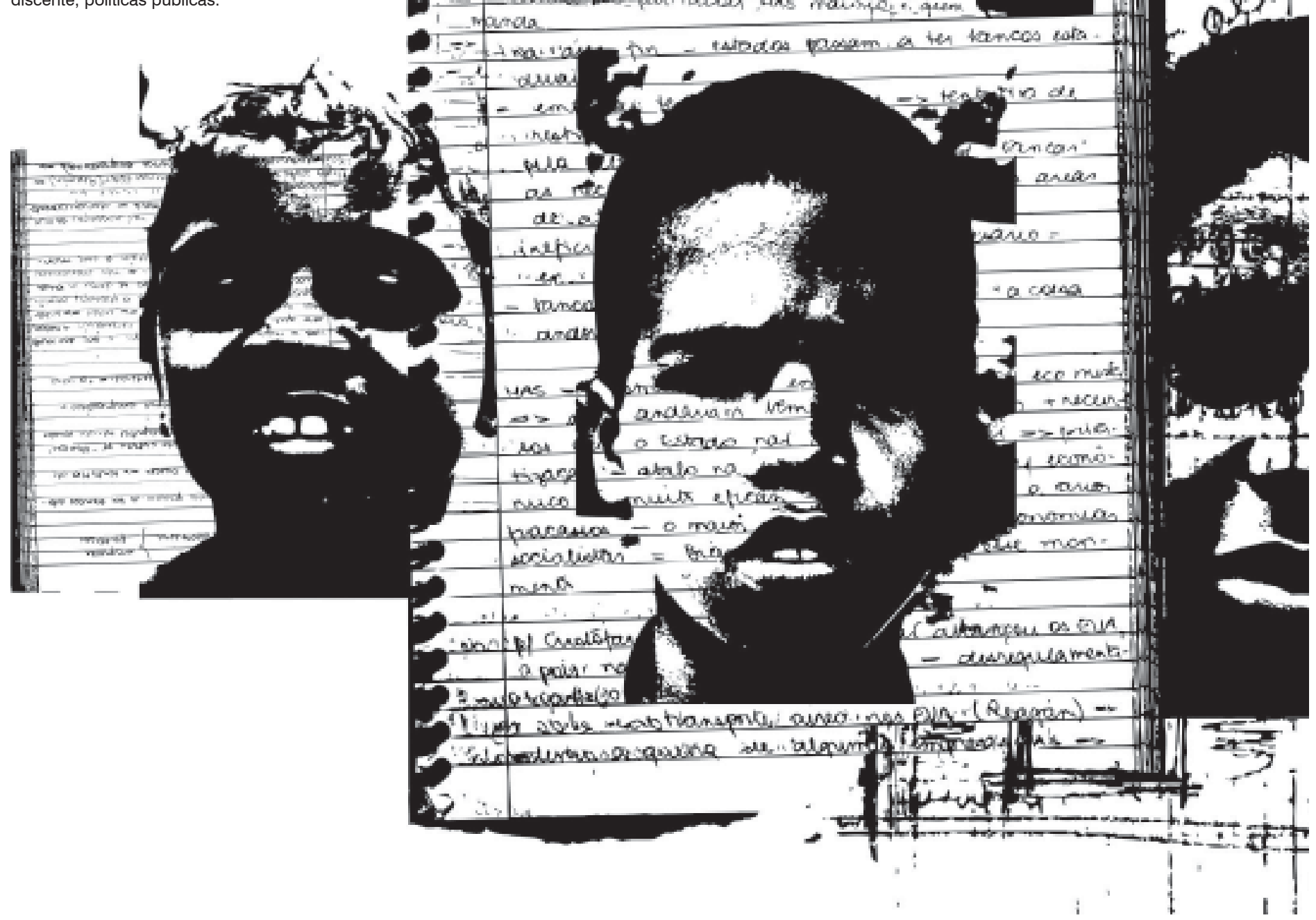




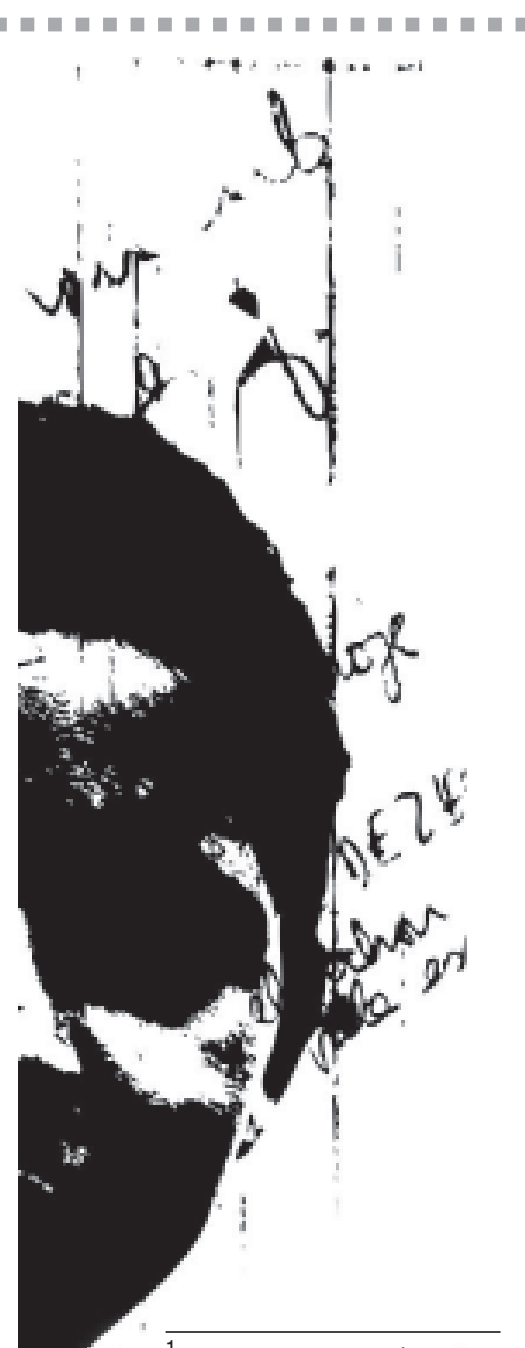

1 Financiado pela Pró-Reitoria de Extensão da Universidade Federal de São Carlos (Proex/UFSCar)

2 O Decreto no 40.473, de $21 / 11 / 95$, promoveu mudanças na organização da rede física das escolas da rede estadual que passaram a se constituídas por classes de $1^{\mathrm{a}}$ a $4^{\mathrm{a}}$ série; de $5^{\mathrm{a}}$ a $8^{\mathrm{a}}$ série e de $2^{\circ}$ grau, e que também alterou a jornada diária de aula de quatro para seis horas, no período diurno, entre outras alterações.
A nalisa comparativamente alguns dados sobre a rede de ensino público do Estado, de um município de porte médio paulista, considerando o número de alunos matriculados, promovidos, retidos; número de abandonos, número de classes e média de alunos por classe, segundo os diferentes setores do sistema de ensino estadual situados no município e os diferentes níveis do ensino, tendo como fonte o Levantamento de Dados Escolares ( $L D E$ ) relativos aos dois anos considerados. Os resultados, ou seja, os indicadores educacionais determinados, indicam alterações derivadas da implementação da "reorganização" e suscitam um conjunto de questões e hipóteses que merecem estudos adicionais voltados para uma melhor compreensão das conseqüências de alterações nas políticas educacionais.

\section{Introdução}

O presente trabalho ${ }^{1}$ contempla uma análise comparativa de alguns dados sobre a rede de ensino público do Estado, de um município de porte médio paulista, em dois momentos distintos: antes (1994) e após a "reorganização" do sistema escolar, em 1996. ${ }^{2}$ É uma derivação de um projeto mais amplo de diagnóstico da rede de ensino do município de São Carlos (SP), cujo objetivo principal foi o de realizar a caracterização dos diferentes aspectos relativos ao fracasso escolar entre outros, tendo em vista o desenvolvimento de ações conjuntas entre a Universidade $\mathrm{Fe}$ deral de São Carlos (UFSCar) e a comunidade, com vistas à superação dos problemas identificados.

Investigar como se caracteriza a realidade escolar, justifica-se quando se considera a existência de inúmeros fatores que, isolados ou em conjunto, têm resultado em um padrão educacional cuja qualidade pode ser questionada, no sentido de não estar promovendo "uma oferta qualificada em termos de proporcionar aos alunos 0 acesso aos bens culturais e aos conhecimentos sistematizados e disponíveis (...) e o desenvolvimento de habilidades cognitivas e atitudinais mais abrangentes" (Franco, 1994).

Uma forma de realizar tal caracterização consiste no monitoramento de sistemas educacionais com a finalidade de melhor compreender os progressos ocorrentes, não apenas no sentido de descrever aspectos referentes à expansão de uma rede de ensino, por exemplo, mas principalmente para analisar a sua efetividade e, em alguns casos, buscar identificar os fatores facilitadores ou impeditivos para a sua realização. Para acompanhar a implementação de estratégias voltadas para ofertas educacionais mais qualificadas e responder às questões decorrentes de seu desenvolvimento, vem aumentando o interesse - por parte da sociedade, em geral, e dos responsáveis pelas políticas públicas, em particular - quanto ao desempenho dos sistemas educacionais, na perspectiva de melhor compreender como elas se desenvolvem para atender aos desafios econômicos e sociais mais amplos.

Para Shavelson e colaboradores (1991), os sistemas de indicadores educacionais têm os mesmos propósitos dos sistemas adotados para o monitoramento da economia, do sistema judiciário ou qualquer outro sistema social. São constituídos de dados estatísticos e podem ser usados para acompanhar condições complexas que provavelmente são julgadas de maneira imprecisa ou incompleta nas observações cotidianas. Os indicadores 
têm como propósito caracterizar a natureza de um sistema por meio de seus componentes - como estão relacionados e como se modificam ao longo do tempo. Estas informações podem ser utilizadas para avaliar o progresso em direção a um objetivo, ou padrão, em relação a algum desempenho passado ou à comparação com dados de outras instituições ou países, por exemplo.

Embora para Nuttall (1994) o conceito de indicador seja algo ainda não muito claro, este autor defende ser mais conveniente discutir os seus usos. Na perspectiva apontada por este autor, os indicadores são planejados para oferecer informações sobre o estado de um sistema educacional ou social e podem constituir instrumentos sinalizadores de que algo possa não estar funcionando bem. Assim, os indicadores per se não oferecem o diagnóstico ou a prescrição de um remédio; apenas sugerem que uma ação é necessária. Os indicadores podem oferecer elementos para a descrição e a identificação de problemas bem como a determinação de pistas para a definição de programas voltados para a superação das dificuldades delineadas.

No geral, os indicadores educacionais podem ser compreendidos como compostos de informações ou estatísticas que refletem aspectos importantes de um sistema educacional. Porém, cabe destacar que nem todas as estatísticas sobre educação podem ser definidas como indicadores. Elas somente podem ser qualificadas como indicadores se informam sobre as condições de alguns aspectos significativos, em particular, por meio de dados sobre um determinado sistema. Por exemplo, embora o número de alunos matriculados em escolas seja um fato importante, pouco diz sobre o funcionamento de um sistema educacional. Por outro lado, o dado sobre a proporção de alunos do curso médio que apresentaram um bom rendimento em Matemática, por exemplo, pode oferecer informações consideráveis sobre a "saúde" de um sistema e ser, desse modo, considerado um indicador. Nesse sentido, um sistema de indicadores é mais do que uma coletânea de dados estatísticos. Idealmente, um sistema de indicadores mede componentes distintos de um sistema e também oferece informações sobre como os componentes individuais funcionam em conjunto para produzir o resultado geral. Em outras palavras, o

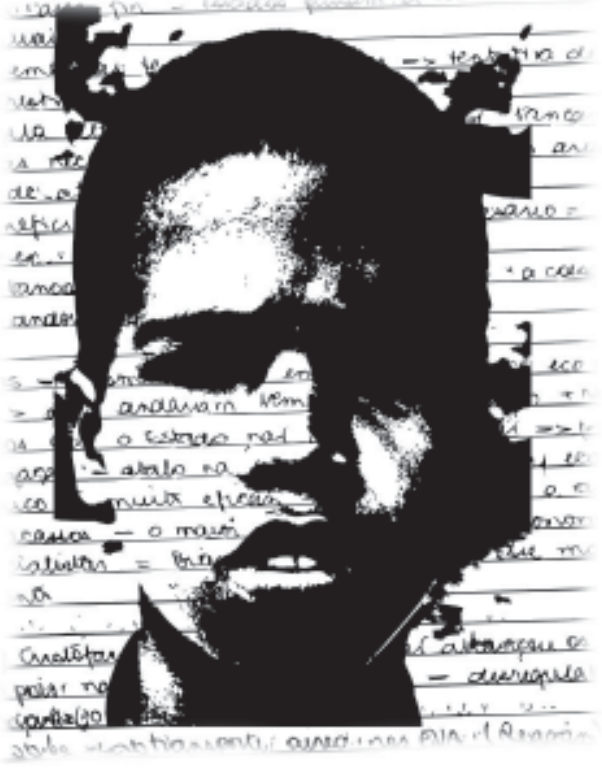

conjunto das informações oferecidas por um sistema de indicadores é maior do que a soma de suas partes.

Para Darling-Hammond e Ascher (1991), os indicadores educacionais são essenciais quando se pensa em educação pública, apesar de as idéias de como utilizá-los virem se modificando ao longo dos últimos anos. A partir de uma análise crítica sobre diversos níveis ou mecanismos de monitoramento dos sistemas educacionais (político, legal, burocrático, profissional, de mercado), por meio de indicadores, essas autoras afirmam não haver uma forma de acompanhamento ideal de tais sistemas, uma vez que a adoção de cada um desses mecanismos apresenta vantagens e desvantagens. O desejável seria o uso combinado de diversos indicadores de modo que diferentes níveis de monitoramento de sistemas educacionais pudessem ser aplicados. Para ilustrar como tais idéias podem ser operacionalizadas, as autoras apontam alguns critérios para a seleção de indicadores educacionais:

- devem ser capazes de detectar os problemas correntes ou as dificuldades potenciais;

- as informações devem ser descritas de modo que indiquem para os responsáveis pelas políticas quais devam ser as metas a serem atingidas;

- os dados devem incluir as taxas de graduação e de abandono; os resultados de avaliações de desempenho; amostras de diversos tipos de produção discente,

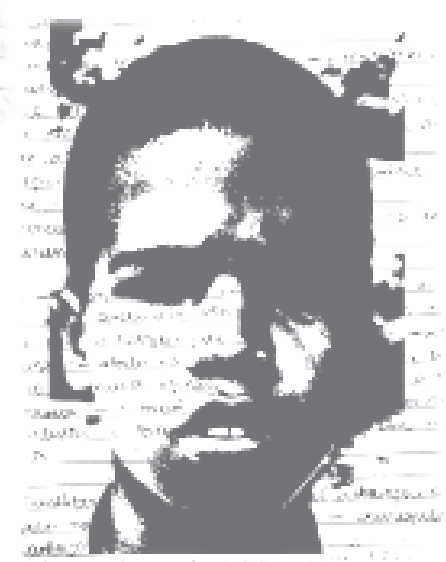




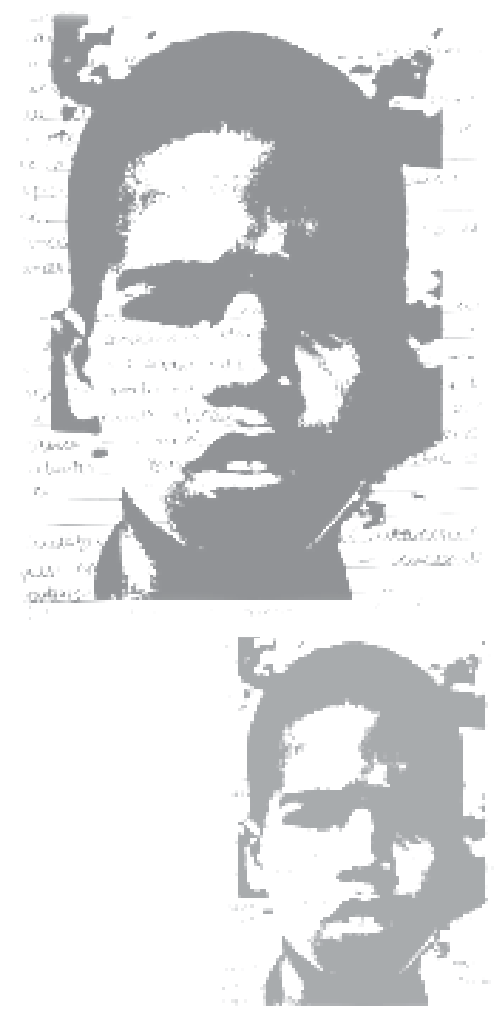

\footnotetext{
3 A progressão continuada preconiza ciclos de aprendizagem ininterrupta, por meio do oferecimento de "todas as oportunidades possíveis para aprender na escola mobilizando recursos como aulas estimulantes, materiais pedagógicos, avaliações constantes, horas de trabalho pedagógico ..." (Progressão continuada, passo a passo. Escola Agora, p. 4, 1998). As retenções ocorrem apenas nas séries finais de cada ciclo caso o aluno apresente freqüência insuficiente desempenho insatisfatório.

4 Formulário que é respondido anualmente por todas as escolas da rede estadual de ensino do Estado de São Paulo.
}

ou seja, devem refletir os resultados do processo educacional;

- não podem ser interpretados de modo significativo sem informações sobre quais são os alunos envolvidos; nos casos em que a população estudantil é altamente móvel, os escores dos testes, por exemplo, que supostamente medem o crescimento dos alunos em diversos momentos, podem efetivamente não estar avaliando os mesmos alunos. Desse modo, os indicadores devem apontar para o background dos alunos;

- os dados sobre o modo pelo qual as escolas são organizadas e quais serviços oferecem são necessários para dar dicas ou pistas sobre o porquê de as escolas apresentarem um tal desempenho, isto é, os indicadores devem ser ilustrativos do contexto escolar.

Segundo Bottani e Tuijnman (1994), o mais importante é que os indicadores forneçam uma das bases para o estabelecimento de novas visões e expectativas, especialmente para os professores considerados como os principais responsáveis pela condução do processo ensinoaprendizagem. De acordo com esta perspectiva, o desenvolvimento de indicadores educacionais não é um exercício meramente técnico e controlado por estatísticos, mas sim um exercício político.

É importante destacar o papel das informações oferecidas pelos indicadores educacionais não apenas para os professores, mas a sua vinculação para o estabelecimento e acompanhamento de novas políticas educacionais por parte de diversos segmentos da sociedade como: pais, alunos, responsáveis pelas políticas públicas, entre outros. No caso específico deste trabalho, conhecer os efeitos de uma nova política educacional sobre alguns aspectos relacionados com o corpo discente favorece ainda a definição de áreas de investigação/intervenção, por parte da Universidade junto à comunidade na qual está inserida.

\section{Objetivos}

Considerando as alterações ocorridas no sistema escolar da rede pública do Estado de São Paulo, ao final de 1995, foram estabelecidos os objetivos deste trabalho. De modo mais específico, tendo em vista a melhoria da qualidade de ensino, a Secretaria de Estado de Educação introduziu um conjunto de medidas que visavam

garantir a oportunidade de escolarização, privilegiando o respeito ao desenvolvimento psicossocial de alunos da mesma faixa etária, mediante a organização de unidades escolares que, de forma coerente e eficaz, reúnam recursos apropriados a esse tipo de atendimento (São Paulo, 1995, p. 1).

Dentre as medidas adotadas, pode-se destacar: a reorganização da rede física, separando-a em escolas para crianças e aquelas para adolescentes, permitindo a implementação de projetos pedagógicos mais adequados a cada faixa etária; a descentralização de repasse de recursos, via Associação de Pais e Mestres; aumento da jornada diária, que foi alterada de quatro para cinco horas e a introdução de horas semanais de recuperação; a implantação do regime de progressão continuada, ou seja, a promoção dos alunos nas diversas séries do Ciclo I (1ํa a $4 \underline{a}$ a série) e do Ciclo II (5 ${ }^{\underline{a}}$ a $8^{\underline{a}}$ série) do ensino fundamental e do ensino médio, ${ }^{3}$ a introdução do Projeto Escola nas Férias, em janeiro de 1997, visando oferecer uma chance maior de recuperação dos alunos que não obtiveram "sucesso no processo tradicional de verificação de aproveitamento na avaliação final de 1996" (São Paulo, 1997b).

Tendo em vista o estabelecimento de uma base nova de conhecimentos que possibilitasse a melhor compreensão dos efeitos da reorganização especialmente sobre os indicadores relativos ao corpo discente, optou-se, no presente trabalho, por sistematizar e comparar o conhecimento derivado da análise do Levantamento de Dados Escolares (LDE) ${ }^{4}$ sobre diversos aspectos da clientela escolar do município de São Carlos (SP), em 1994 e 1996. As análises foram conduzidas considerando dados como: número de alunos matriculados, promovidos, retidos, evadidos, número de classes e média de alunos por classe.

A análise crítica de indicadores educacionais sobre diferentes aspectos relativos ao corpo discente, derivados de levantamentos oficiais referentes a um dado período de tempo - no caso de 1994 a 1996 -, pode constituir um exercício importante para o estabelecimento de 
elementos informativos adicionais que fomentem a discussão de aspectos políticoeducacionais e de práticas pedagógicas de um contexto educacional específico, num período de mudanças.

De modo mais específico, no presente estudo, procurou-se verificar quais as informações constantes nos LDEs de 1994, referentes ao corpo discente, foram mantidas em 1996; de que natureza são; como estas informações podem ser organizadas compondo um sistema de indicadores educacionais sobre o corpo discente; e outros aspectos relacionados que permitisse identificar e analisar as mudanças nos resultados obtidos no período em pauta.

\section{Metodologia}

A coleta e a análise de indicadores educacionais nos moldes sugeridos implicaram a adoção de um enfoque metodológico tal que permitisse a apreensão, interpretação e descrição das informações consideradas relevantes. Para tanto, foram reproduzidos os LDEs dos anos de $1994 \mathrm{e}$ 1996 de todas as escolas da rede estadual de ensino de São Carlos (SP) existentes na Diretoria de Ensino e, em seguida, foram inseridos num banco de dados criado especificamente para a realização deste trabalho. Optou-se por essa fonte oficial por apresentar os dados para cada unidade escolar do município e ser de fácil acesso, apesar das restrições que podem ser feitas com relação à confiabilidade dos dados apresentados por parte das escolas nestes formulários, já que alguns erros podem ocorrer no seu preenchimento.

A análise baseou-se na caracterização dos diferentes setores ${ }^{5}$ do sistema de ensino estadual ${ }^{6}$ e dos diferentes níveis do ensino (séries iniciais e $5^{\mathrm{a}}$ a $8^{\mathrm{a}}$ série do ensino fundamental, ensino médio regular e profissionalizante), por meio dos indicadores selecionados, na perspectiva de possibilitar a ampliação do significado dos dados constantes nos LDEs. A consideração dos diferentes setores permitiu o confronto entre as ocorrências evidenciadas em escolas localizadas no centro da cidade que atendem, em princípio, a uma clientela socioeconômica e cultural mais diferenciada - em relação àquela relativa às escolas localizadas em bairros mais periféricos e mais desfavorecidos.

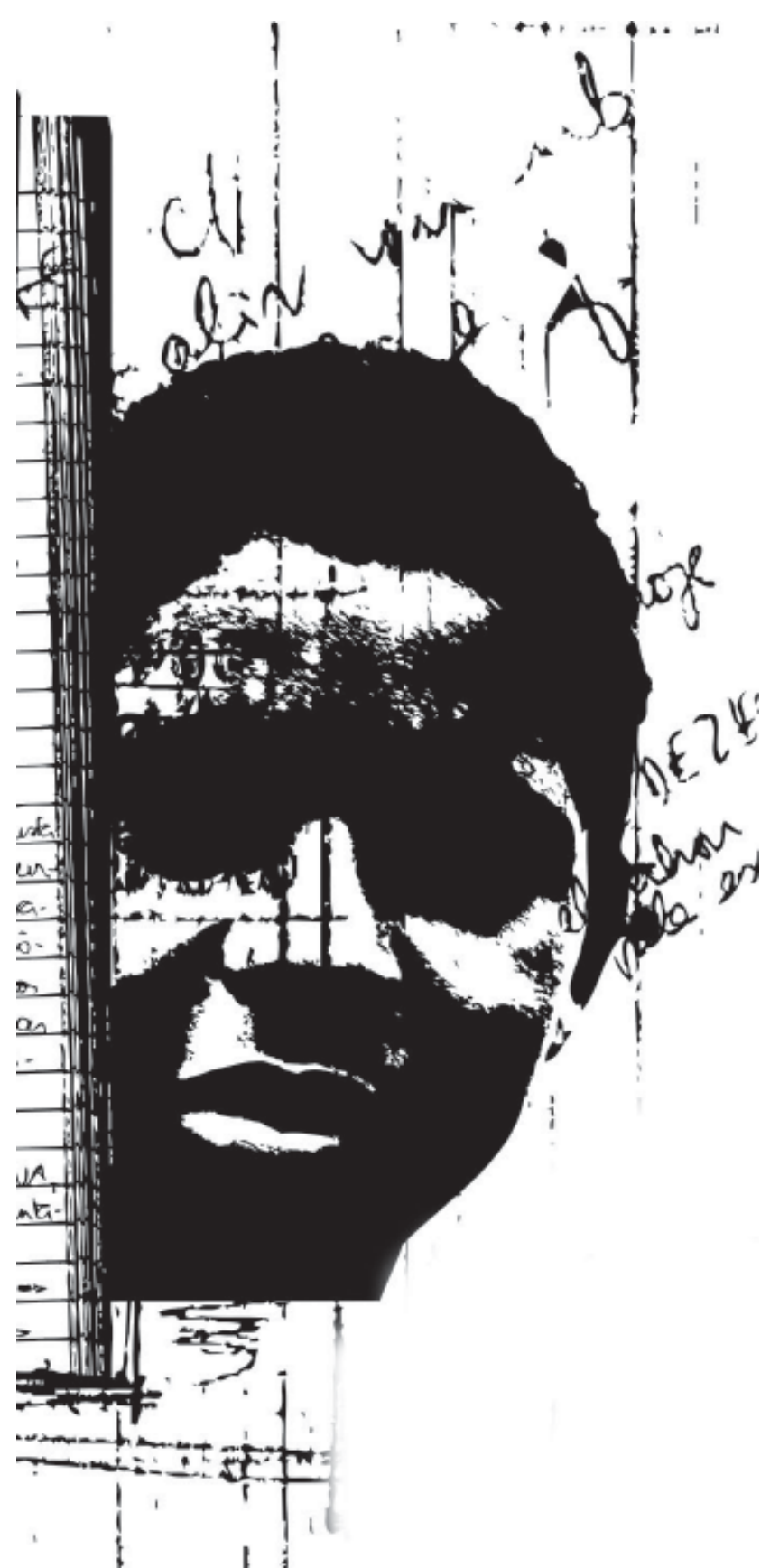

O seguinte conjunto de variáveis foi considerado na realização das análises: número de alunos matriculados no início do ano, número de classes, média de alunos por classe, aprovações, abandonos e reprovações. Para o estabelecimento dos porcentuais no caso dos abandonos, reprovações e aprovações, foram considerados como parâmetros os dados de matrícula inicial, isto é, o número total de alunos matriculados ao final do mês de março dos dois anos analisados. Esta decisão teve como propósito permitir uma visão mais clara das ocorrências, tendo como referência as informações do seu
5 O município de São Carlos era subdividido em oito setores geográficos, segundo classificação adotada por parte da Diretoria de Ensino nessa ocasião. No geral, os setores relacionados com os números de $1 \mathrm{a} 4$ correspondem àqueles situados nas regiões mais centrais e antigas do município. Os setores 5, 6, 7 e 8 correspondem às regiões mais afastadas do centro da cidade onde se localizam bairros populares.

6 A análise foi limitada à rede estadual, uma vez que no ano de 1996 as escolas das redes municipal e particulares deixaram de responder aos LDEs. 
início. Desse modo, a soma dos porcentuais obtidos para os casos indicados pode resultar num valor diferente de $100 \%$.

A idade dos alunos, transferências recebidas e efetuadas não foram analisadas por não estarem disponíveis para o ano de 1996 apesar de, sob o nosso ponto de vista, constituírem-se informações relevantes para a compreensão de algumas dinâmicas do processo de escolarização, como a distorção idade/série e a "movimentação de alunos" pela rede de ensino. No primeiro caso, os dados oferecem elementos para o levantamento de hipóteses sobre o modo pelo qual as escolas "lidam" com parte de seus alunos, ou mesmo hipóteses relacionadas com a existência de retenções prévias, abandonos anteriores seguidos de retorno para a escola - que podem inclusive ser confirmadas a partir da análise das trajetórias acadêmicas dos alunos. No segundo caso, o confronto quanto ao número de alunos transferidos - sejam os recebidos ou aqueles que se dirigem para outros estabelecimentos escolares - pode ser um indicador importante quanto ao desempenho geral do aluno numa dada série além de fornecer informações importantes sobre a movimentação de alunos num dado sistema de ensino. Por exemplo, em 1994 cerca de $6,7 \%$ (1.056) dos alunos das séries iniciais, $8,1 \%(1.193)$ de quinta a oitava série e $5,2 \%$ (418), considerando as redes municipal, estadual e particular de ensino, localizadas no município de São Carlos (SP), solicitaram ao longo do ano letivo transferência da escola em que originalmente se matricularam (Reali, 1997). O destino destes alunos bem como o que motivou a necessidade de mudança de escola são informações ainda pouco conhecidas. Pode-se supor que parte deste conjunto de alunos tenha solicitado a transferência para outras escolas, no geral consideradas mais fáceis e localizadas em setores mais periféricos do município, quando se dão conta de que é possível que sejam retidos na sua escola de origem.

\footnotetext{
7 Denominação do ensino fundamental e médio antes da promulgação da nova LDB.

8 Até 1996 correspondia à atual 1 a série.

9 Até 1996 correspondia à atual $2^{\mathrm{a}}$ série.
}

séries do ensino fundamental e do ensino médio, conforme indicação anterior.

Em São Carlos (SP), esta modificação não alterou o número total de unidades escolares (30) vinculadas à rede estadual de ensino em relação a 1994, embora se tenha observado em cada um dos oito setores, aqui tomados como referência para as análises apresentadas a seguir, a redistribuição nas ofertas de vagas e níveis de ensino. Por exemplo, escolas de $10 \mathrm{e}$ $2^{\circ}$ graus $^{7}$ passaram a atender apenas de 5 a 8 a série e/ou o ensino médio enquanto as antigas escolas de 10 grau passaram a oferecer, no geral, apenas classes de $1 \underline{a}$ a 4a série.

Num primeiro momento, os resultados referentes ao ensino regular serão apresentados separadamente e de modo mais detalhado, levando-se em conta os diferentes setores. Posteriormente, os mesmos dados serão analisados em conjunto, de modo a permitir uma visão geral sobre os aspectos relativos ao corpo discente da rede estadual nos dois anos considerados.

\section{0 ensino fundamental}

\section{a) Séries iniciais}

As séries iniciais são compostas das quatro primeiras séries do ensino fundamental e no início de 1996 havia um total de 11.403 alunos matriculados nessas séries em escolas da rede estadual. A sua comparação com dados relativos a 1994 (12.334) evidencia uma redução geral de $7,5 \%$ de alunos atendidos neste nível e rede de ensino, indicando assim o grande primeiro efeito da reorganização.

Do total de alunos em 1996, 22,3\% estavam matriculados na $1^{\text {a }}$ série; $28,2 \%$ na $2^{\mathrm{a}}$ série; $26,9 \%$ na $3^{\mathrm{a}}$ série e $22,5 \%$ na $4^{a}$ série. Em 1994, observou-se a seguinte distribuição dos alunos: $24,9 \%$ estavam matriculados no Ciclo Básico Iniciante (CBI), ${ }^{8} 27,1 \%$ no Ciclo Básico Continuidade (CBC), ${ }^{9} \quad 25,1 \%$ na $3^{a}$ série e $22,9 \%$ na $4^{\text {a }}$ série. Nota-se em 1996 uma distribuição menos uniforme de alunos ao longo das quatro séries em relação a 1994; a existência de um maior porcentual de alunos na $2^{a}$ série em relação às demais séries e uma diminuição gradual no porcentual de alunos à medida que as três séries seguintes se sucedem tal como em 1994. 
A análise do número de alunos matriculados, segundo o setor freqüentado, indicou algumas diferenças nos dados considerados em 1996 de modo semelhante ao observado em 1994. Com a reorganização da rede, houve a redistribuição no número de alunos matriculados nas escolas situadas nos diferentes setores (Gráfico 1). Nota-se um aumento no número de alunos atendidos nos setores 1,5 , e 8 e uma diminuição nos demais setores.

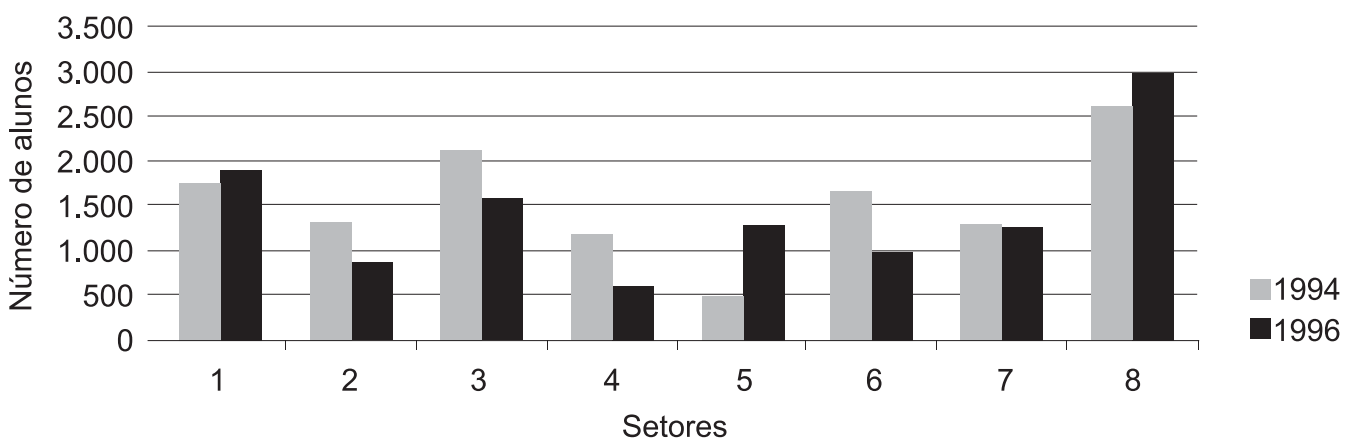

Gráfico 1 - Número de alunos da $1^{\mathrm{a}}$ à $4^{\mathrm{a}}$ série do ensino fundamental da rede estadual, nos diferentes setores do município de São Carlos (SP), nos anos de 1994 e 1996

Fonte: LDE, 1994 e 1996.

Relativamente ao número de classes das séries iniciais em funcionamento, havia um total de 337 classes de 1 a a $4^{\underline{a}}$ série no ano de 1996 - 28 classes a menos do que o registrado para o ano de
1994, isto é, menos $7,6 \%$. A diferença no número de classes evidenciada em cada setor é coerente com a variação no número de alunos, como pode ser observado no Gráfico 2.

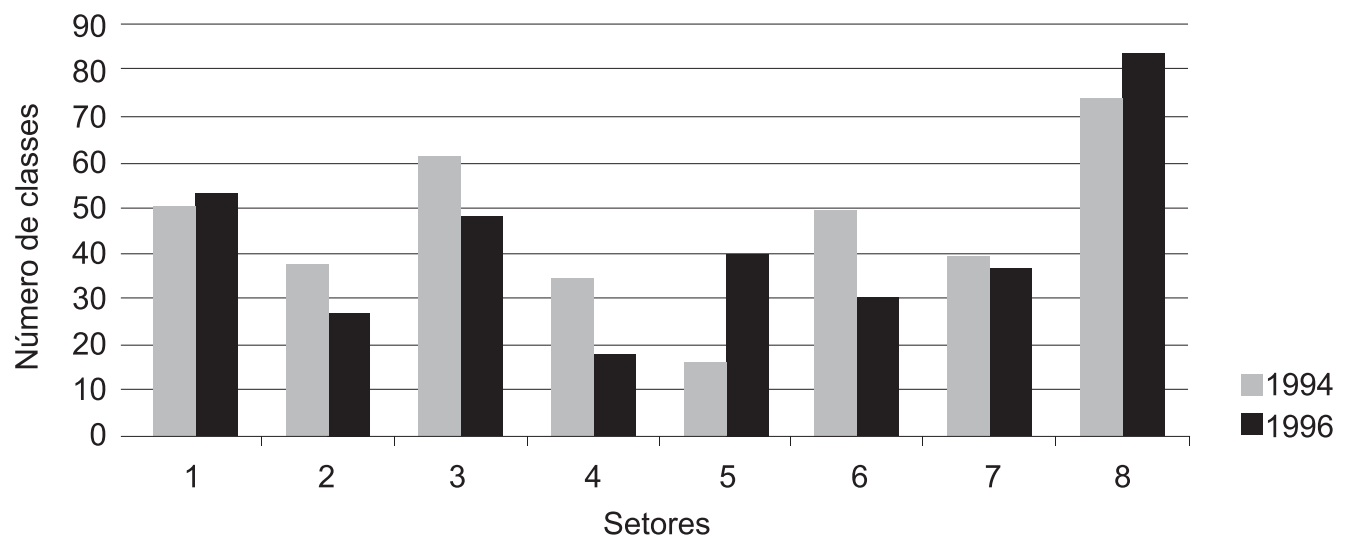

Gráfico 2 - Número de classes da 1a à 4⿳亠丷a série do ensino fundamental da rede estadual, nos diferentes setores do município de São Carlos (SP), nos anos de 1994 e 1996

Fonte: LDE, 1994 e 1996.

É possível verificar uma diminuição da média de alunos por classe, nos setores 2 , 3 e 4 , e um aumento nos demais, quando os resultados referentes aos dois anos são considerados. Os resultados evidenciados para os setores 6 e 7 indicam uma diminuição no número de alunos e de classes em 1996 em relação a 1994. Esses dados, 
por sua vez, indicam ter havido um aumento após a reorganização quanto ao número médio de alunos atendidos por classe. Eles sugerem que a diminuição observada no número de classes teve um efeito mais evidente nestes setores, quando se leva em conta o número de alunos atendidos.
Os setores cujos resultados apresentaram um aumento na média de alunos por classe caracterizam-se genericamente por ser, exceto no caso do setor 1 , aqueles mais periféricos e compostos de bairros cujo nível socioeconômico é mais baixo em relação às regiões mais centrais da cidade (Gráfico 3).

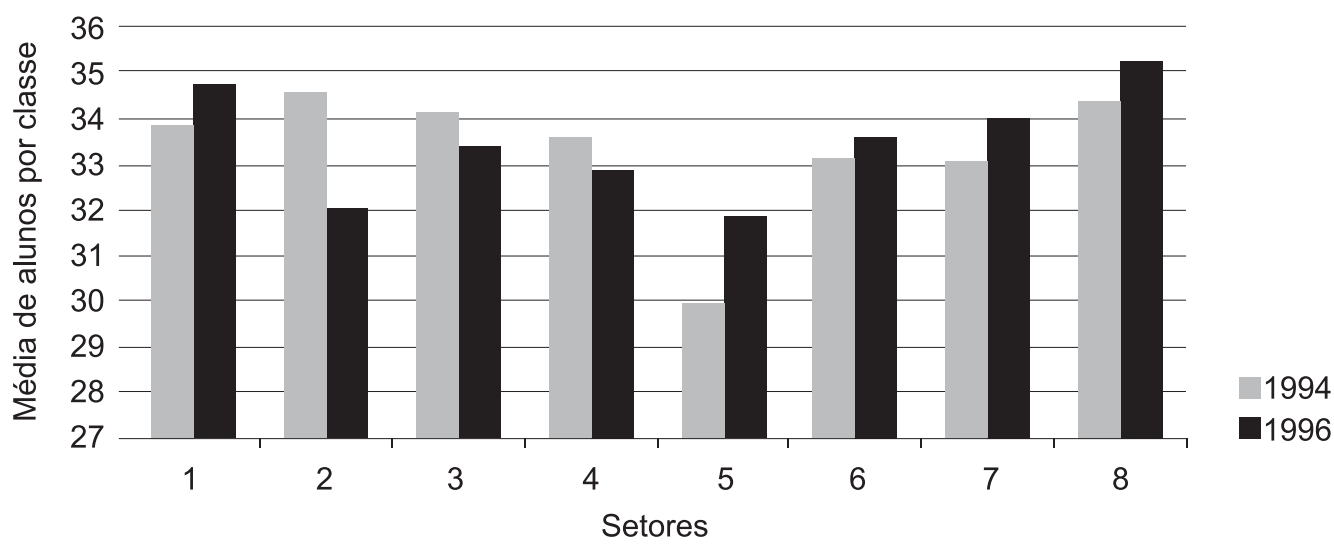

Gráfico 3 - Média de alunos por classe da $1^{\mathrm{a}}$ à $4^{\mathrm{a}}$ série do ensino fundamental da rede estadual, nos diferentes setores do município de São Carlos (SP), nos anos de 1994 e 1996

Fonte: LDE, 1994 e 1996

Com relação aos aspectos considerados para o cálculo da matrícula total, ${ }^{10}$ verifica-se que, em 1996, 3,7\% dos alunos inicialmente matriculados afastaram-se por abandono; $1,5 \%$ foi retido por freqüência; $7,6 \%$ foram retidos por avaliação e $87,2 \%$ foram promovidos. ${ }^{11}$ Cabe destacar ser este último dado superior ao indicado para o Estado de São Paulo como um todo 83,8\% de aprovação neste nível de ensino (São Paulo, 1997a). Em 1994, os dados indicam que $6,9 \%$ dos alunos inicialmente matriculados afastaram-se por abandono; $0,2 \%$ foi retido por freqüência; $10,0 \%$, foram retidos por avaliação e $79,8 \%$ foram aprovados. Observa-se, para as quatro séries em conjunto, quando os dados de 1996 e 1994 são comparados, um decréscimo no caso daqueles afastados por abandono, dos retidos por avaliação e um aumento no caso dos retidos por freqüência e, no caso dos alunos promovidos, evidenciou-se um acréscimo de 7,5\%.
No Gráfico 4 é possível observar para cada uma das quatro séries iniciais como estes aspectos se configuraram em 1994 e 1996.

Nota-se em 1996 a mesma configuração determinada para 1994: após a 2ª série, ocorre uma redução nos porcentuais de afastamento por abandono e de retenção por avaliação, com um aumento nos resultados de promoção à medida que as séries avançam até a $4^{a}$ série.

Os mesmos resultados apresentados, de acordo com os setores em que se localizam as escolas (Gráfico 5), indicam que o aumento na porcentagem de alunos aprovados e a diminuição nos dados de abandono e de retenção por avaliação ocorreram de modo mais acentuado em alguns setores do que em outros. Destacase que as reduções nos porcentuais de abandono e de retenção por avaliação são mais acentuadas nos setores mais centrais do município de São Carlos (SP). 


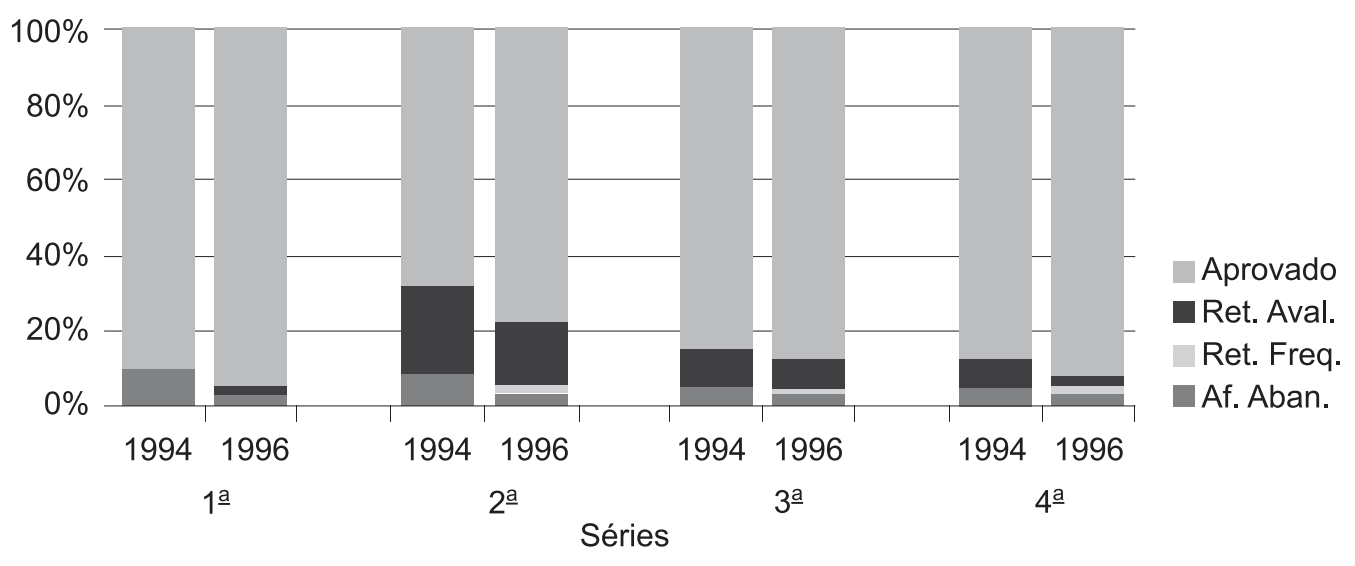

Gráfico 4 - Matrícula total da $1^{\mathrm{a}}$ à $4^{\mathrm{a}}$ série do ensino fundamental da rede estadual do município de São Carlos (SP), nos anos de 1994 e 1996 (em porcentagem) Fonte: LDE, 1994 e 1996.

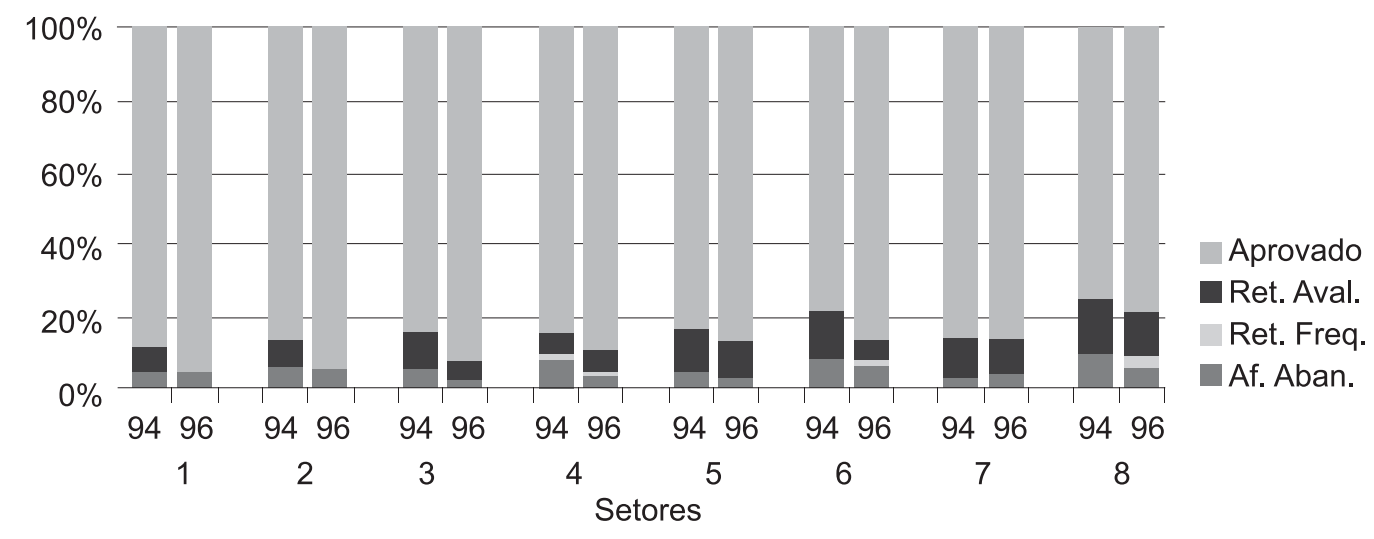

Gráfico 5 - Matrícula total da $1^{\mathrm{a}}$ à $4^{\mathrm{a}}$ série do ensino fundamental da rede estadual, nos diferentes setores do município de São Carlos (SP), nos anos de 1994 e 1996 (em porcentagem)

Fonte: LDE, 1994 e 1996.

b) 5aa a $8^{\underline{a}}$ série

No início do ano letivo de 1996, havia 11.255 alunos matriculados entre a $5^{\mathrm{a}}$ e a $8^{\mathrm{a}}$ série do ensino fundamental, dos quais $30,1 \%$ estavam matriculados na $5^{\mathrm{a}}$ série; $25,0 \%$ na $6^{a} ; 22,6 \%$ na $7^{\mathrm{a}}$ e $22,3 \%$ na $8^{\mathrm{a}}$ série. Em 1994, havia um contingente maior de alunos nestas séries (11.656): 29,7\% estavam matriculados na 5 a série; $28,0 \%$ na 6루 $22,9 \%$ na 7 a e $19,4 \%$ na 8 a série. Estes dados evidenciam uma diminuição no total de alunos atendidos e no número de alunos matriculados, à medida que estas séries se sucedem quando os dois anos são considerados.

Ao se observar a maioria dos setores, verifica-se a apresentação de poucas variações no número de alunos, quando são considerados os anos de 1994 e 1996, exceto nos casos do setor 1 - no qual se determinou uma diminuição acentuada e do setor $4 \mathrm{em}$ que ocorreu o inverso, isto é, um aumento (Gráfico 6).

Havia, para essas séries, um total de 305 classes em 1996, o que significou uma oferta de 27 classes $(8,4 \%)$ a menos do que em 1994. No Gráfico 7 pode-se notar que a diminuição só não foi observada nos setores 3 e 4.

Com relação à média de alunos por classe (Gráfico 8) em todos os setores, houve um aumento, de cerca de 2,2 alunos por sala, em 1996. Os maiores aumentos observados na média de alunos por classe ocorreram nos setores que representam as regiões periféricas do município (setores $5,6,7$ e 8). 


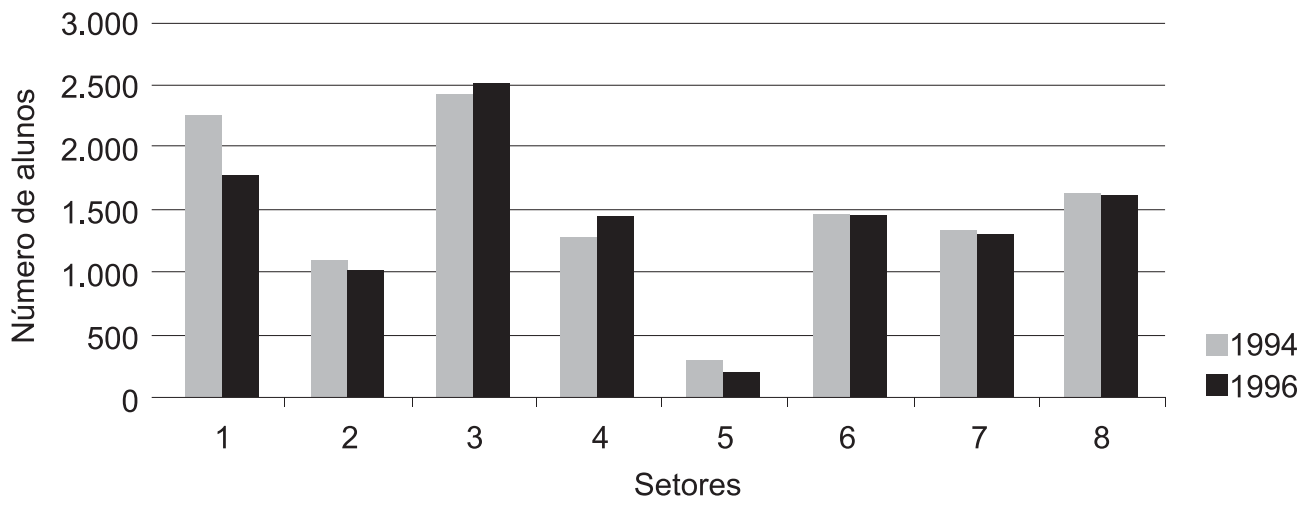

Gráfico 6 - Número de alunos de $5^{\mathrm{a}}$ a $8^{\mathrm{a}}$ série do ensino fundamental da rede estadual, nos diferentes setores no município de São Carlos (SP), nos anos de 1994 e 1996

Fonte: LDE, 1994 e 1996

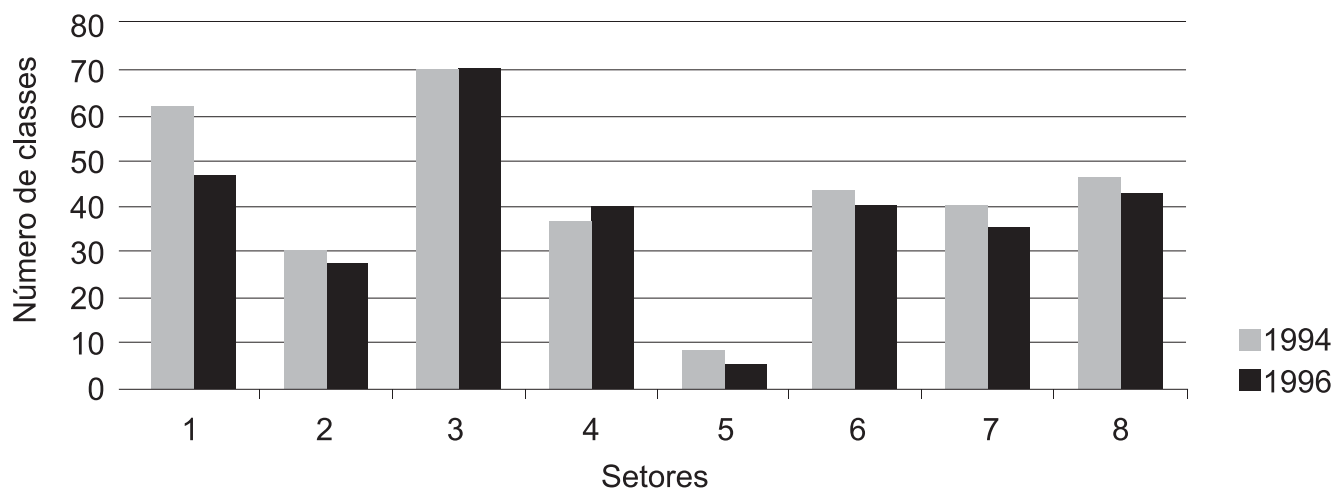

Gráfico 7 - Número de classes de $5^{\mathrm{a}}$ a $8^{\mathrm{a}}$ série do ensino fundamental da rede estadual, nos diferentes setores no município de São Carlos (SP), nos anos de 1994 e 1996.

Fonte: LDE, 1994 e 1996

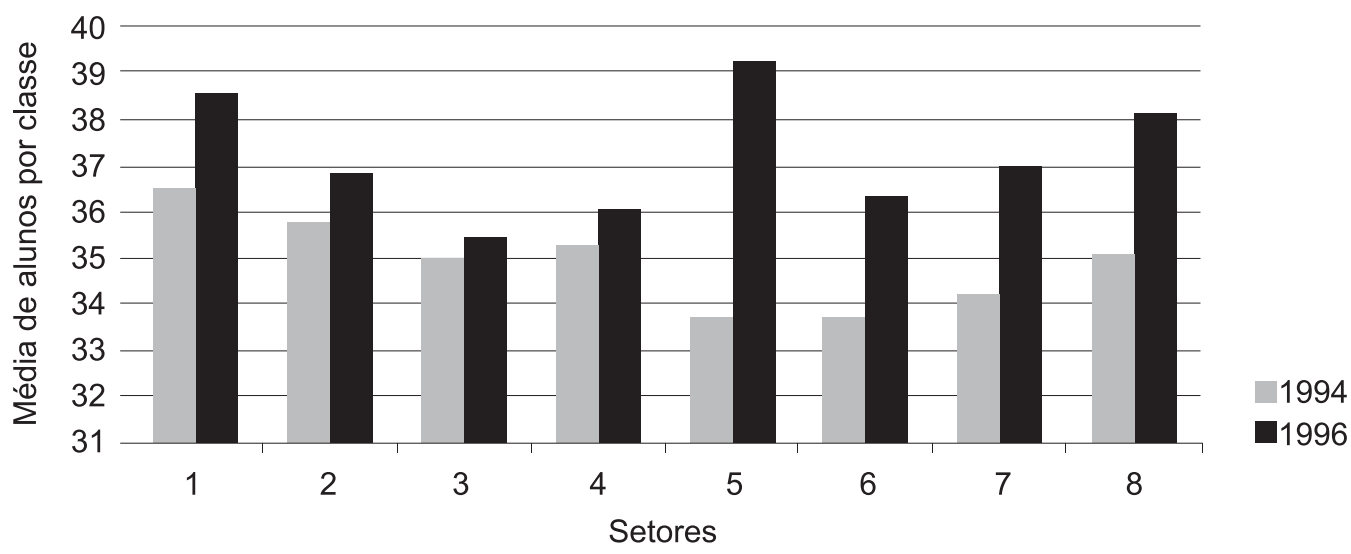

Gráfico 8 - Média de alunos por classe de $5^{\mathrm{a}}$ a $8^{\mathrm{a}}$ série do ensino fundamental da rede estadual, nos diferentes setores no município de São Carlos (SP), nos anos de 1994 e 1996

Fonte: LDE, 1994 e 1996 
Com relação aos aspectos considerados para o cálculo da matrícula total, 7,9\% dos alunos inicialmente matriculados na rede estadual afastaram-se por abandono; $0,5 \%$ foi retido por freqüência; $8,9 \%$ foram retidos por avaliação e $80,2 \%$ foram promovidos em 1996. Em 1994, 9,7\% dos alunos foram afastados por abandono; $0,04 \%$ foi retido por freqüência; $9,7 \%$ foram retidos por avaliação e 79,5\% foram aprovados.
Os resultados finais dos alunos em 1996 tiveram pouca variação se comparados aos de 1994, exceto para os da $5^{\mathrm{a}}$ série, na qual se verifica um índice menor de afastados por abandono, o que pode estar relacionado com o aumento no porcentual de aprovados (Gráfico 9). Nos dois anos aqui considerados, notase que à medida que as séries avançam, há uma diminuição nos porcentuais de abandono e de retenção por avaliação e

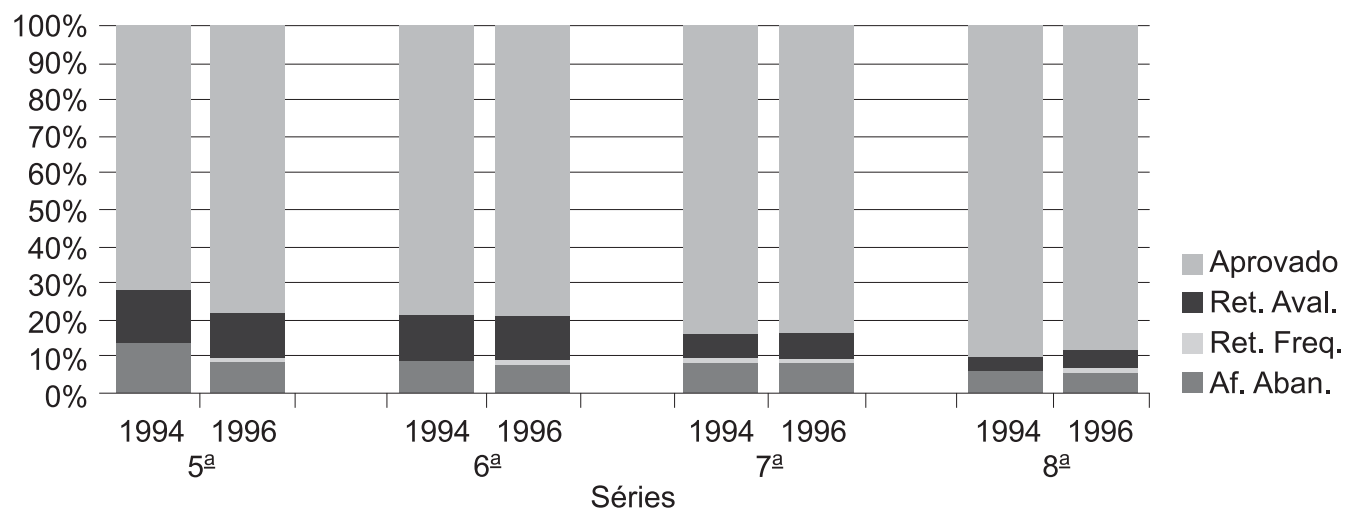

Gráfico 9 - Matrícula total de $5^{\mathrm{a}}$ a $8^{\mathrm{a}}$ série do ensino fundamental da rede estadual, no município de São Carlos (SP), nos anos de 1994 e 1996 (em porcentagem) Fonte: LDE, 1994 e 1996.

um conseqüente aumento nos porcentuais de aprovação, sugerindo como no caso das séries iniciais, ser esta etapa escolar também seletiva, no sentido de que possivelmente, cada ano a mais de escolaridade, as chances aumentam de o aluno permanecer na escola no futuro.
Apesar de o porcentual de aprovação não ter se alterado de 1994 a 1996 (79,5\% para $80,2 \%$ ), em alguns setores do município evidenciam-se algumas diferenças como pode ser observado no Gráfico 10. É evidente a diminuição dos porcentuais de aprovação nos setores 5 e 7 . O setor 5

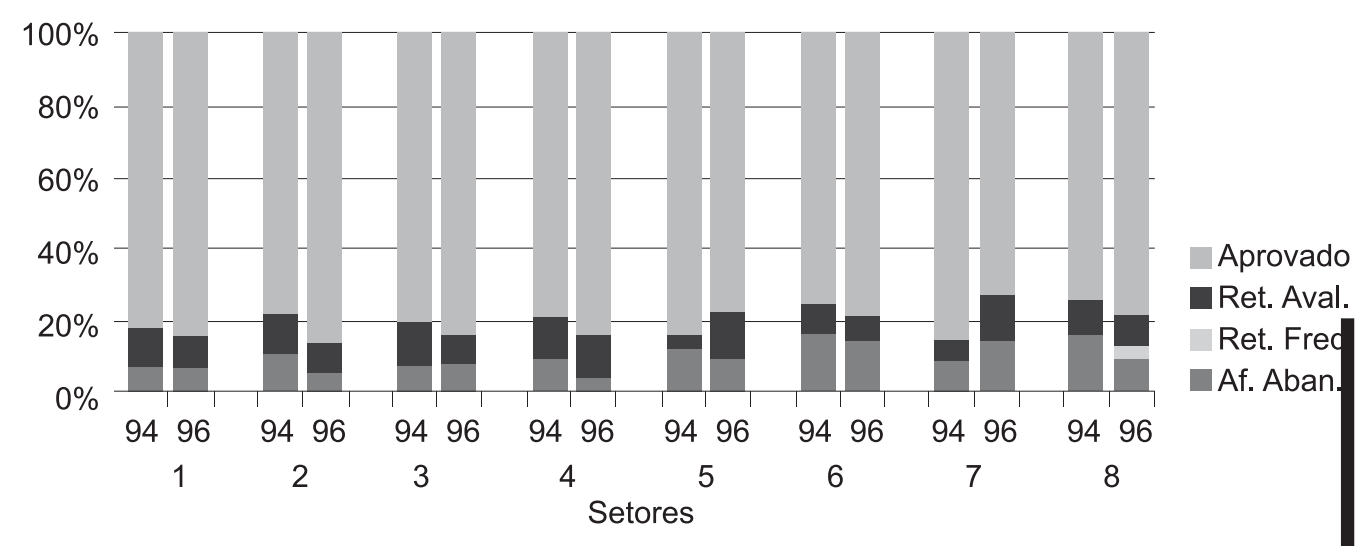

Gráfico 10 - Matrícula total de $5^{\mathrm{a}}$ a $8^{\mathrm{a}}$ série do ensino fundamental da rede estadual, nos diferentes setores no município de São Carlos (SP), nos anos de 1994 e 1996 (em porcentagem) 
apresentou um aumento expressivo de alunos retidos por avaliação, e no setor 7 verificou-se o aumento de alunos retidos por avaliação e também de afastados por abandono, quando os anos de 1994 e 1996 são comparados. De modo semeIhante ao evidenciado para as séries iniciais, notou-se um aumento nos porcentuais de retidos por freqüência no setor $8 \mathrm{em}$ 1996.

\section{c) O processo de recuperação nas férias}

Outra das modificações introduzidas no sistema estadual de ensino no caso do ensino fundamental foi a oferta de uma recuperação denominada de "Escola nas Férias" e oferecida no mês de janeiro de 1997. Este programa foi criado com a intenção de "propiciar maiores chances de sucesso" por meio de aulas que têm como objetivo oferecer aos alunos repetentes "reforço especial nos conteúdos não assimilados que impediram a progressão no período letivo regular" (São Paulo, 1997b, p. 1).

No geral, o número de inscritos (811) foi inferior ao número de reprovados por avaliação durante o período letivo regular, pelo menos com relação aos alunos do ensino fundamental (1874). Os resultados apresentados indicam que o número de alunos aprovados, ao final de janeiro, foi muito inferior ao número de alunos inscritos, independentemente do turno freqüentado, sugerindo ser esta estratégia importante, embora não tenha apresentado os efeitos desejados (Gráfico 11).

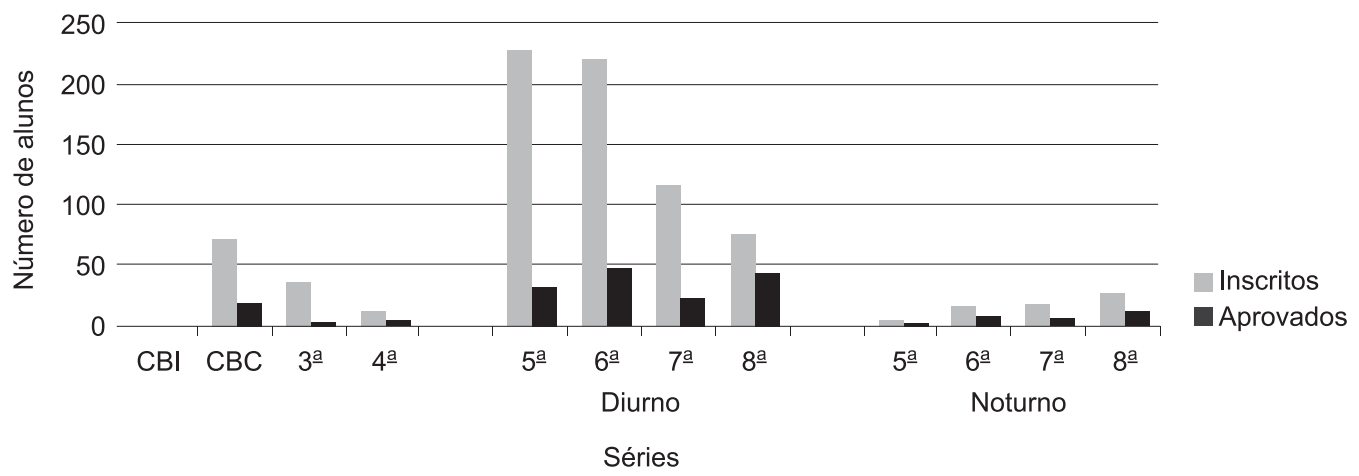

Gráfico 11 - Inscritos e aprovados na recuperação de férias nas diferentes séries do ensino fundamental da rede estadual, no município de São Carlos (SP), no ano de 1996

Fonte: LDE, 1994 e 1996

\section{0 ensino médio}

A análise do material relativo ao ensino médio indicou, no início de 1996, haver 6.597 alunos matriculados. Deste total, $47,8 \%$ estavam matriculados no $1^{\circ}$ ano, $29,0 \%$ no $2^{\circ}$ ano, $21,2 \%$ no $3^{\circ}$ ano e $1,9 \%$ no $4^{\circ}$ ano de magistério (único curso profissionalizante oferecido pela rede estadual em 1996 - dados do LDE desse ano - e cuja duração é de quatro anos).
Em 1994, havia 6.539 alunos assim distri-

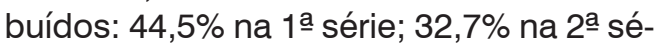
rie; $18,2 \%$ na 3aㅡ série e $4,5 \%$ na 4a série. Conforme já observado para as duas etapas do ensino fundamental, evidenciou-se a diminuição no número de alunos ao longo das diferentes séries do ensino médio.

De modo semelhante a 1994, a rede estadual não está presente com este nível de ensino em todos os setores do município de São Carlos (SP), apesar de ter 
havido o estabelecimento de uma escola estadual de ensino médio no setor 6 (Gráfico 12). Observa-se, ainda, uma concentração maior de alunos no setor 1, em relação aos demais setores, embora tenha havido um pequeno aumento com relação ao número de alunos nos setores 2 ,
3 e 8 , quando os dados dos dois anos são considerados.

As alterações no número de classes oferecidas em 1996 pela rede de ensino estadual acompanharam as variações ocorridas com o número de alunos nos diferentes setores (Gráfico 13).

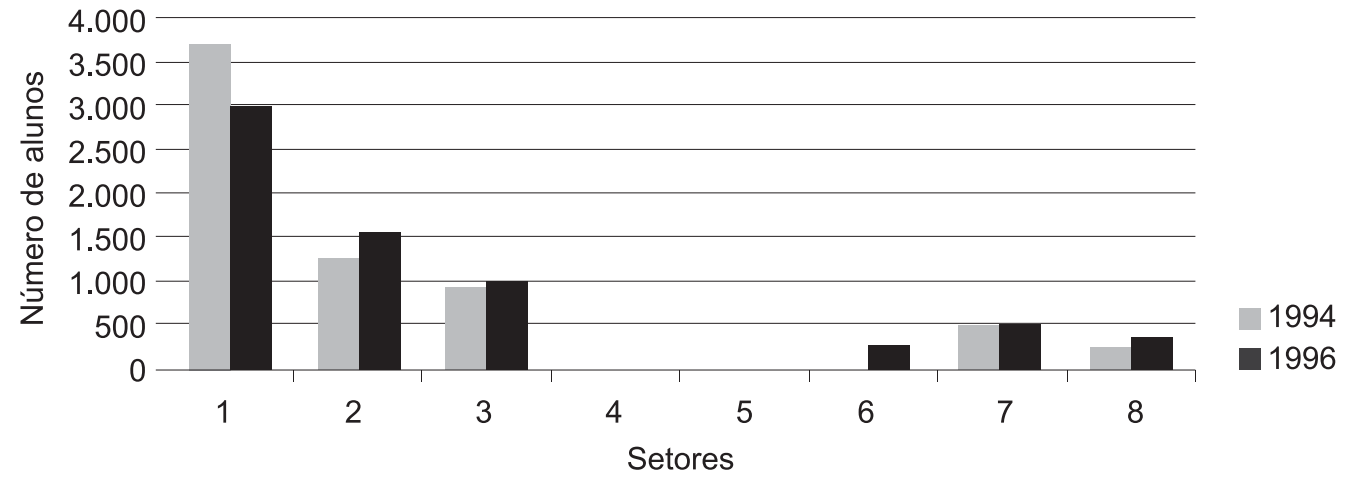

Gráfico 12 - Número de alunos do ensino médio da rede estadual, nos diferentes setores no município de São Carlos (SP), nos anos de 1994 e 1996

Fonte: LDE, 1994 e 1996.

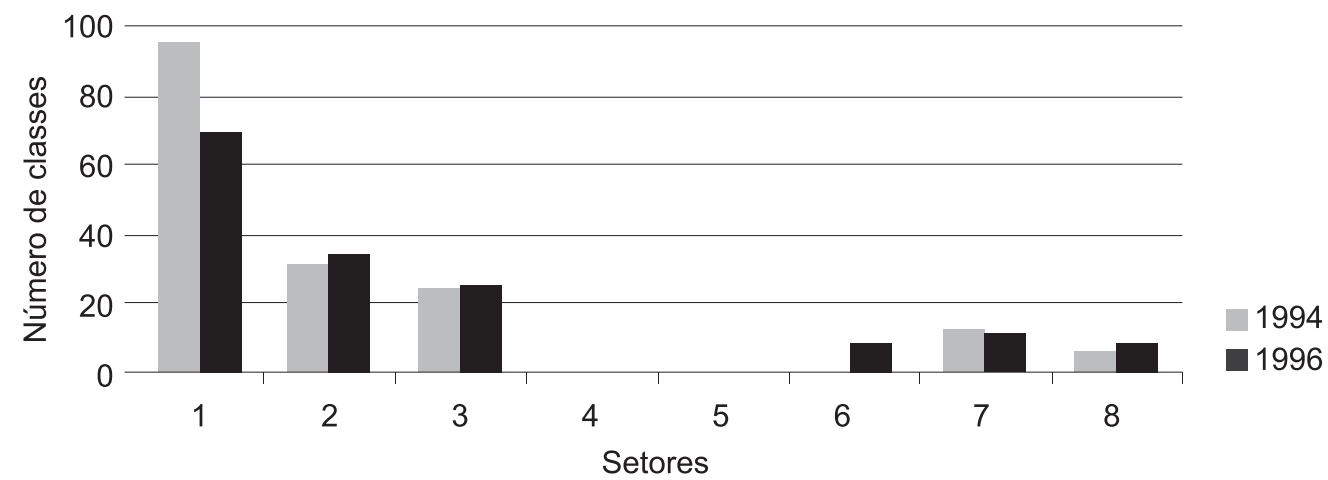

Gráfico 13 - Número de classes do ensino médio da rede estadual nos diferentes setores no município de São Carlos (SP) nos anos de 1994 e 1996

Fonte: LDE, 1994 e 1996.

Em 1994, havia um total de 168 classes e em 1996, 155, o que implica uma redução geral de aproximadamente $8,0 \%$. Investigações adicionais parecem necessárias para determinar se tais mudanças atenderam às demandas reais destes locais.
Assim, como nos outros níveis analisados, houve um aumento no número médio de alunos por classe, e é importante ressaltar que este nível de ensino já apresentava em 1994 uma média de alunos superior ao restante do ensino regular (Gráfico 14). 


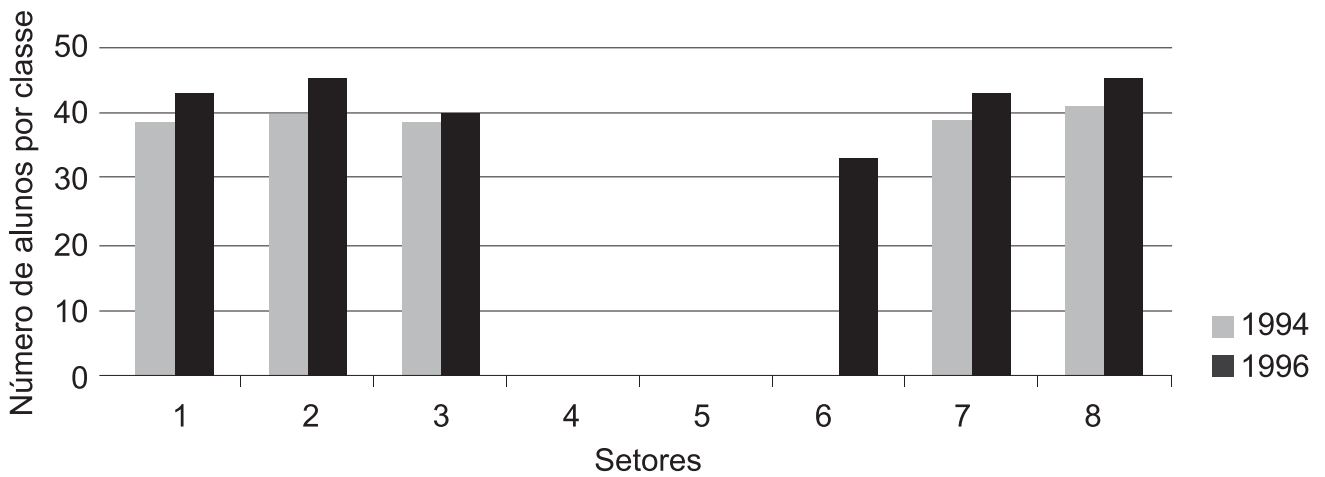

Gráfico 14 - Média de alunos por classe do ensino médio da rede estadual, nos diferentes setores no município de São Carlos (SP), nos anos de 1994 e 1996

Fonte: LDE, 1994 e 1996.

Com relação à matrícula final, notamse diferenças mais acentuadas quanto aos resultados finais da 1 a série do ensino médio, e os das demais séries são considerados de modo semelhante ao observado para os dados referentes a 1994 (Gráfico 15). De modo mais específico, tem-se a ocorrência dos maiores índices de abandono e de retenção do ensino médio na 1 a série.
Considerando o conjunto das séries do ensino médio em 1996, evidencia-se que $14,5 \%$ dos alunos do ensino médio abandonaram a escola antes do final do ano letivo; $0,1 \%$ foi retido por freqüência; $11,7 \%$ foram retidos por avaliação e $73,6 \%$, promovidos. Está claro que à medida que estas séries se sucedem, há um aumento nos porcentuais de aprovação e uma redução dos porcentuais de retenção e de

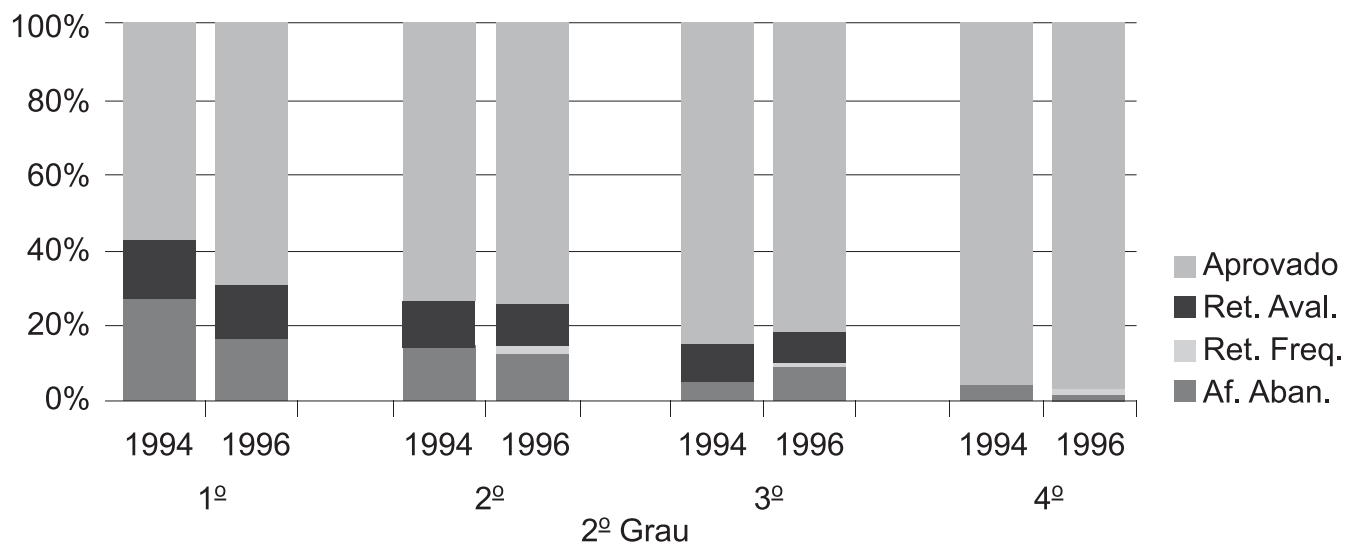

Gráfico 15 - Matrícula total do ensino médio da rede estadual no município de São Carlos (SP), nos anos de 1994 e 1996 (em porcentagem)

Fonte: LDE, 1994 e 1996

abandono, de modo similar ao observado para o ensino fundamental. Estes dados são consistentes com aqueles indicados pela Secretaria Estadual da Educação do Estado de São Paulo - relativos a 1996, ou seja, de $75,2 \%$ de promoção e $16,6 \%$ de evasão. Os dados de 1996 comparados ainda com os de 1994 indicam algumas alterações nos resultados finais dos alunos, já que naquela ocasião $19,6 \%$ dos alunos foram afastados por abandono; $0,04 \%$ foi retido por freqüência; $12,6 \%$ foram retidos por avaliação e $71,5 \%$ foram promovidos. 
Quando os resultados finais são considerados por setor (Gráfico 16), percebe-se que o setor 2, que apresentava uma alta incidência de retenção e de abandono em 1994, passou a apresentar um dos maiores porcentuais de aprovação em 1996. Nos demais setores, observa-se uma redução nos dados relativos ao abandono (exceto no setor 3 ), e o aumento nos dados de retenção (exceto no setor 2). Contudo, o abandono continua sendo o maior problema deste nível de ensino, como é possível observar por meio dos dados de 1994 e 1996.

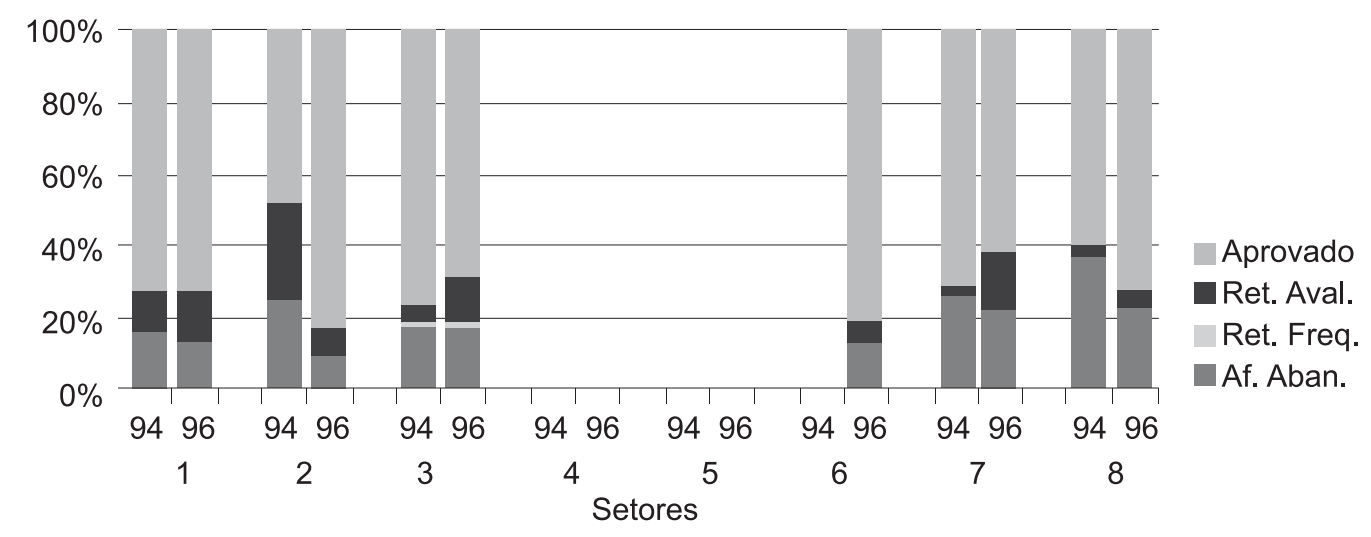

Gráfico 16 - Matrícula total do ensino médio da rede estadual, nos diferentes setores no município de São Carlos (SP), nos anos de 1994 e 1996 (em porcentagem) Fonte: LDE, 1994 e 1996.

Uma visão geral sobre a rede estadual de ensino em São Carlos (SP): 1994-1996

A distribuição dos alunos de acordo com o nível de ensino em 1994 e 1996 é apresentada na Tabela 1. Pode-se notar uma diminuição no número de alunos atendidos pela rede estadual em $1996 \mathrm{em}$ relação a 1994, embora tenha sido mantido o mesmo número de unidades escolares conforme já mencionado. Havia $32.611^{12}$ alunos matriculados nos diferentes níveis de ensino no início do ano letivo de 1996, enquanto em 1994 havia o registro de 33.322 alunos. Em linhas gerais, verificou-se uma diminuição no número de alunos matriculados no ensino fundamental e um aumento no número de alunos do ensino supletivo e ensino especial na rede estadual de ensino.

A comparação do número de alunos do ensino regular nos anos considerados indica que a $8^{a}$ série do ensino fundamental e a 1a e 3a séries do ensino médio apresentam número maior de alunos em 1996 em relação a 1994. Nas $1^{a}, 4^{a}$ e $6^{a}$ séries do ensino fundamental, notam-se reduções de $17,1 \% ; 9,0 \%$, e 13,8\% respectivamente.

Tabela 1 - Número de alunos atendidos pela rede estadual em 1994 e 1996 São Carlos (SP)

\begin{tabular}{|c|c|c|c|}
\hline Nível de ensino & 1994 & 1996 & Variação (\%) \\
\hline 1a a 4⿳亠丷a série & 12.334 & 11.403 & $-7,5$ \\
\hline $5^{\mathrm{a}}$ a $8^{\mathrm{a}}$ série & 11.656 & 11.255 & $-3,4$ \\
\hline Ensino médio & 6.539 & 6.597 & 0,9 \\
\hline Ensino supletivo (1ํ sem.) & 2.765 & 3.318 & 20,0 \\
\hline Educação especial & 28 & 38 & 35,7 \\
\hline Total & 33.322 & 32.611 & $-2,1$ \\
\hline
\end{tabular}

Fonte: LDE, 1994 E 1996. 
As outras séries apresentaram reduções cujos índices não ultrapassaram 5,0\%, como é o caso da 7 a série. No ensino médio, nota-se um aumento no número de alunos atendidos nas $1 \stackrel{\text { a }}{\text { e }}$ 3a séries e uma diminuição na $2^{\underline{a}}$ e na 4 a série, esta última ligada ao curso de magistério. As variações foram de $6,6 \% ;-13,7 \% ; 11,7 \%$ e $-57,0 \%$ para as $1 \stackrel{a}{a}, 2^{a}, 3 \underline{a}$, e $4^{a}$ séries do $2^{\underline{a}}$ grau, respectivamente (Gráfico 17).

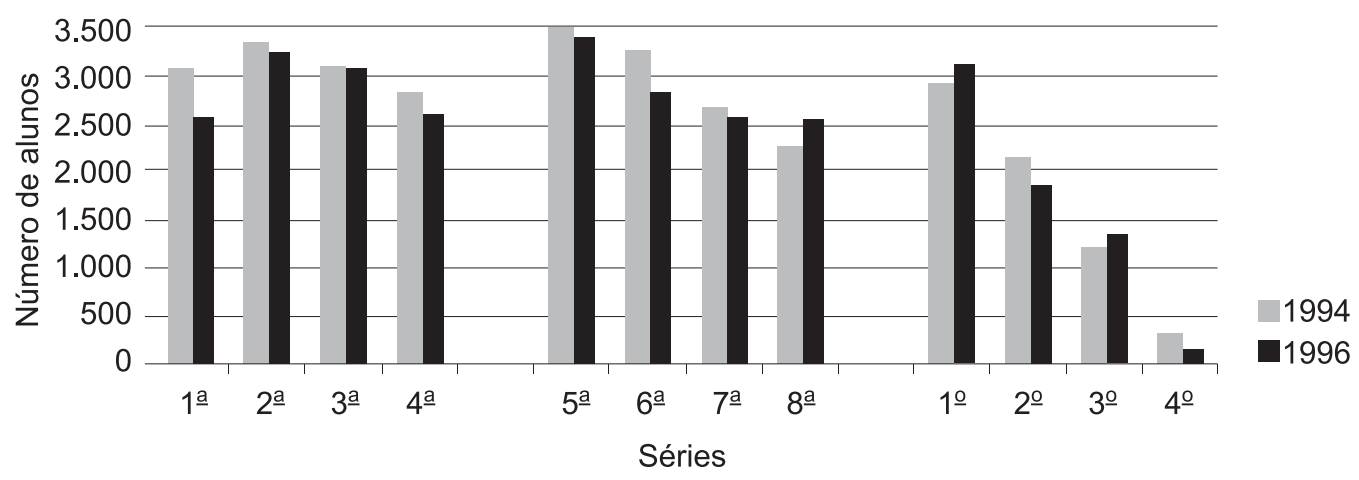

\section{Gráfico 17 - Número de alunos em cada uma das séries do ensino regular da rede estadual no município de São Carlos (SP), nos anos de 1994 e 1996 \\ Fonte: LDE, 1994 e 1996.}

Investigações adicionais são necessárias para a determinação das causas destas diferenças. As variações positivas podem ser justificadas, em parte, por uma tendência de crescimento dos índices de aprovação, o que naturalmente aumenta o fluxo de alunos ao longo das séries, entretanto, questiona-se por que este fenômeno não ocorre de modo consistente ao longo de todas as séries. As variações negativas podem ser explicadas como efeito da política da rede estadual em diminuir a oferta de vagas para o ensino fundamental, especialmente as das séries iniciais, possivelmente tendo em vista acelerar o processo de municipalização do ensino em São Carlos (SP). No caso do curso de magistério (4a a série do ensino médio), acredita-se que a redução possa ser explicada pelas mudanças previstas na nova Lei de Diretrizes e Bases da Educação Nacional (LDB) a respeito da formação de professores bem como da desvalorização social desta profissão.

Alterações também foram verificadas com relação ao número de classes cuja diminuição geral aparentemente acompanhou a redução no número de alunos da rede estadual (Gráfico 18). Adicionalmente e atendendo a uma orientação política,

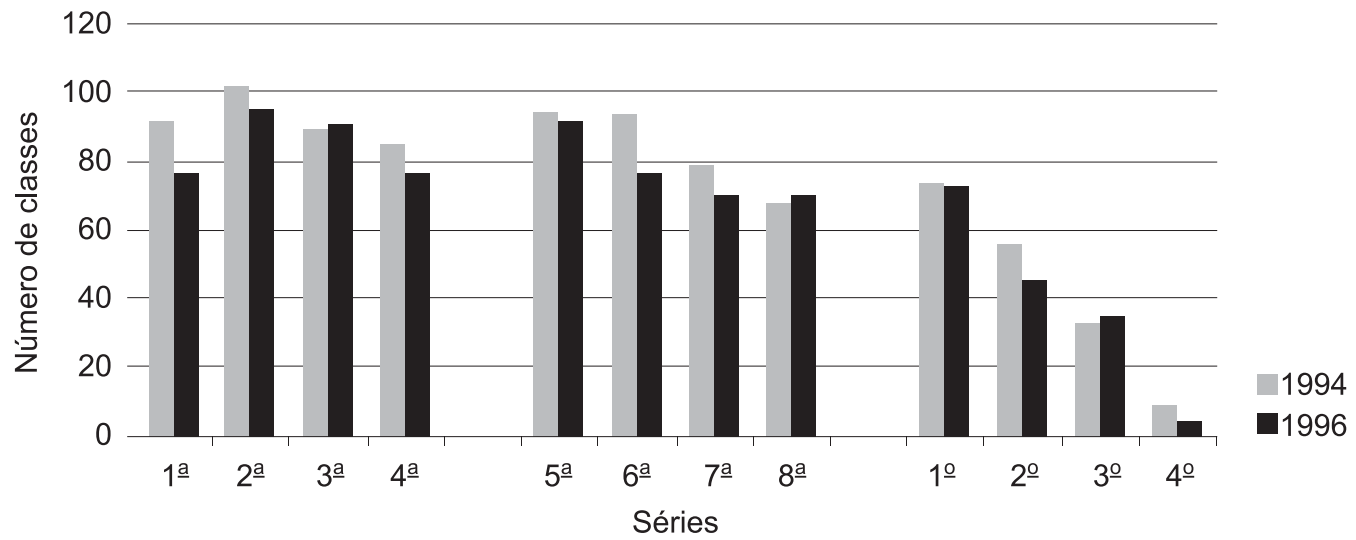

Gráfico 18 - Número de classes oferecidas para cada uma das séries do ensino regular da rede estadual no município de São Carlos (SP), nos anos de 1994 e 1996 Fonte: LDE, 1994 e 1996. 
determinou-se em 1996, em comparação a 1994, uma menor oferta de vagas nos turnos da manhã $(-2,60 \%)$, intermediário $(-22,2 \%)$, tarde $(-4,4 \%)$ e vespertino $(-50,0 \%)$, e um aumento no caso do turno da noite $(19,1 \%)$. Os resultados dos turnos intermediário e vespertino são consistentes com o aumento de horas de cada um dos outros turnos considerados. ${ }^{13}$

Nas séries iniciais, poucas foram as alterações observadas com relação à média de alunos atendidos por classe, enquanto as demais séries se caracterizavam por atender a um maior número de alunos/classe em 1996 - especialmente a partir da 5 a série do ensino fundamental (Gráfico 19). Apenas duas séries apresentaram uma diminuição no número médio de alunos por classe: a 3a série do ensino fundamental e $\circ$ 4으 ano de magistério (ensino médio).

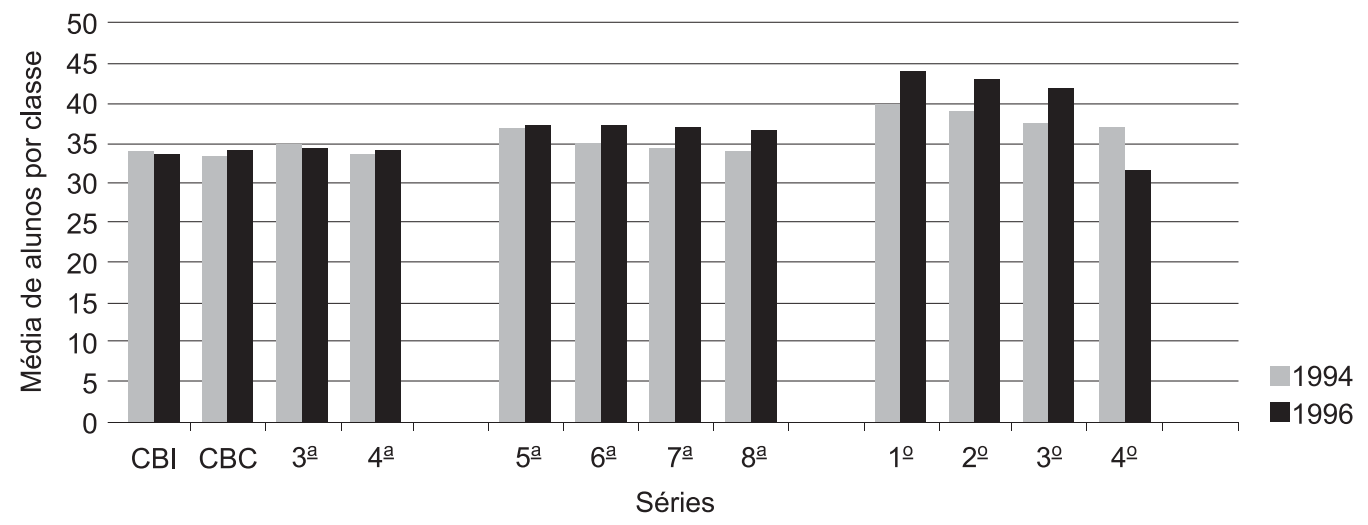

\section{Gráfico 19 - Média de alunos por classe no ensino regular da rede estadual, no}

município de São Carlos (SP), nos anos de 1994 e 1996

Fonte: LDE, 1994 e 1996.

Em relação aos resultados finais de 1996, a Tabela 2 indica um maior "efeito" nas séries iniciais das medidas adotadas por meio do projeto de "reorganização", quando os dados por série são analisados de modo agregado. O mesmo pode ser afirmado, quando são considerados os dados de abandono, que sofreram uma redução, e os de promoção, que foram superiores em relação àqueles definidos

Tabela 2 - Resultados finais dos alunos da rede estadual em São Carlos (SP), em 1994 e 1996

\begin{tabular}{|c|c|c|c|}
\hline Nível/Séries & $\begin{array}{l}\text { Condição do aluno } \\
\text { ao final do ano letivo }\end{array}$ & $1994(\%)$ & $1996(\%)$ \\
\hline \multirow{4}{*}{$\begin{array}{l}\text { Ensino } \\
\text { fundamental/ } \\
\text { 1a a 4a séries }\end{array}$} & Abandono & 5,5 & 3,7 \\
\hline & Retido p/ freqüência & 0,2 & 1,5 \\
\hline & Retido p/ avaliação & 8,9 & 7,6 \\
\hline & Aprovado & 83,9 & 87,1 \\
\hline \multirow{4}{*}{$\begin{array}{l}\text { Ensino } \\
\text { fundamental/ } \\
5^{\underline{a}} \text { a } 8^{\text {a }} \text { séries }\end{array}$} & Abandono & 8,0 & 8,1 \\
\hline & Retido p/ freqüência & 0,07 & 0,5 \\
\hline & Retido p/ avaliação & 11,6 & 9,1 \\
\hline & Aprovado & 82,6 & 82,3 \\
\hline \multirow{4}{*}{ Ensino Médio } & Abandono & 16,8 & 14,5 \\
\hline & Retido p/ freqüência & 0,04 & 0,1 \\
\hline & Retido p/ avaliação & 11,0 & 11,7 \\
\hline & Aprovado & 70,3 & 73,6 \\
\hline
\end{tabular}


para 1994. Não se pode esquecer ainda o fato de os dados obtidos para a recuperação realizada em janeiro de 1997 terem sido pouco positivos, no caso específico do ensino fundamental.

Uma análise mais detalhada dos resultados finais possibilita afirmar, em linhas gerais, ter havido uma redução nos índices de abandono para quase todas as séries do ensino fundamental e ensino médio; redução nos índices de retenção por avaliaçẩo no ensino fundamental; aumento nos porcentuais de aprovação nas séries iniciais e no ensino médio em 1996 em relação a 1994.

\section{4 e 1996: realidades diferentes?}

O presente estudo evidenciou que a implantação do processo de "reorganização" em conjunto com outras medidas, como o funcionamento de salas-ambiente, a progressão automática e a recuperação no mês de janeiro, gerou um quadro educacional em 1996, em muitos aspectos, diverso daquele delineado em $1994 .{ }^{14}$

Os dados relativos a 1996 indicam claramente uma redução na oferta dos serviços da rede estadual de ensino, já que houve um menor número de alunos atendidos e de classes oferecidas, especialmente no ensino fundamental. Entretanto, esta redução não ocorreu uniformemente em todos os setores da cidade de São Carlos (SP). Os setores correspondentes às regiões mais periféricas $\mathrm{e}$, possivelmente, as mais carentes, apresentaram um aumento no número de alunos de certo modo inconsistente com o aumento no número de classes em funcionamento em 1996 no caso das séries iniciais. Estes dados sugerem uma "migração" dos alunos deste nível de ensino, das regiões mais centrais da cidade em direção à periferia, compatível com a política de "reorganização". Há, ainda, a possibilidade de que nestes locais a maior oferta de vagas e classes não ter atendido adequadamente à demanda em 1996, quando se considera o número médio de alunos por classe superior ao observado em 1994.

Os dados relativos às $5^{a}$ e $8^{a}$ séries do ensino fundamental também indicam uma redução no número de alunos em 1996, porém de forma menos acentuada ao evidenciado no caso das séries iniciais. Além disso, os resultados da presente caracterização apontam, neste caso, que a redução ocorreu em apenas um dos setores mais centrais da cidade, sem ter sido acompanhada de um acréscimo correspondente com relação ao número de alunos matriculados e nem de uma maior oferta de classes nos demais setores. Ao contrário, determinou-se uma diminuição no número de alunos, nessa fase da escolaridade, em grande parte dos setores que compõem a rede estadual de ensino analisada.

Quando os dados do ensino médio são considerados, evidencia-se um ligeiro aumento no número de alunos atendidos, apesar de, no geral, o número de classes ter sido reduzido em 1996, quando comparado aos resultados obtidos para 1994.

A partir destes resultados, supõe-se que a rede estadual esteja gradualmente deixando de atender prioritariamente às séries iniciais, principalmente quando se tem a redução de alunos matriculados em cerca de $17,1 \%$, evidenciada para a 1 a série. Simultaneamente, parece que a rede estadual está procurando "otimizar" a oferta das demais séries do ensino fundamental, quando o aumento no número médio de alunos em cada uma das classes é considerado.

Evidenciou-se ainda a existência de diferenças nos resultados obtidos, quando se leva em conta o setor ao qual as escolas consideradas se vinculam, independentemente do ano considerado. No geral, aqueles mais periféricos (setores 5, 6, 7 e 8) apresentam resultados "piores" em relação aos mais centrais.

Os resultados, ou seja, os indicadores educacionais, determinados por meio deste estudo, suscitam um conjunto de questões e hipóteses que merecem estudos adicionais, voltados para uma melhor compreensão das conseqüências de alterações nas políticas educacionais sobre 0 corpo discente, tendo em vista um período de tempo determinado. Em particular, três aspectos se destacam.

Em primeiro lugar, os dados sugerem que a diminuição no número de alunos atendidos está relacionada possivelmente com a municipalização progressiva da rede estadual, especialmente no caso das séries iniciais. Este processo impõe, para a rede municipal, desafios relacionados com a oferta de escolas e vagas compatíveis com as demandas demográficas por setor do município. Como a construção e o estabelecimento de escolas não são feitos de "um dia para outro" e houve uma redução nos serviços oferecidos por parte das escolas 
"reorganizadas" da rede estadual, suspeita-se que muito provavelmente em 1996 um determinado contingente de crianças permaneceu "fora" do sistema regular de ensino. A validade desta hipótese parece ser reforçada quando se considera que, apesar de o crescimento demográfico em São Carlos (SP) apresentar uma tendência em diminuir nos últimos anos, conforme os dados constantes no Perfil socioeducacional das escolas paulistas (1999), muito provavelmente esta diminuição não ocorreu na mesma proporção da redução de vagas oferecidas pela rede estadual e com uma compatível maior oferta das outras redes de ensino (municipal e particular). Deixar crianças fora do sistema escolar parece um efeito inconcebível de políticas educacionais nos dias atuais.

Em segundo lugar, destacam-se os aumentos evidenciados nos porcentuais gerais de aprovação que, apesar dos efeitos supostamente positivos, possivelmente não estão relacionados com as alterações significativas nas práticas pedagógicas dos professores da rede estadual e, por conseqüência, na qualidade da aprendizagem dos alunos. Estas possibilidades se apresentam ao considerar-se que, no geral, mudanças no trabalho docente caracterizam processos e usualmente demandam um tempo longo para que seus efeitos possam ser observados. Aparentemente, estes resultados estão mais relacionados com a adesão da rede estadual à política de progressão automática dos alunos. Sem dúvida, a retenção é "negativa em qualquer sistema de ensino" (Mainardes, 1998), mas acredita-se que o mero "aprovar" alunos também seja negativo. Ao considerar-se que os indivíduos passam após o término dos ciclos, como é o caso do ensino médio, a portar certificações altamente valorizadas socialmente, mas que em realidade estão precariamente habilitados - uma vez que o domínio dos conteúdos escolares se faz de modo parcial -, questiona-se o valor social e o estatuto ético de políticas educacionais que permitem tais ocorrências.

Finalmente, a relação evidenciada entre condições, como média de alunos por classe, o setor no qual as escolas se localizam e os resultados finais relativos à realidade investigada, sugerem que as atuais políticas educacionais, implementadas na rede estadual de São Paulo, não estão privilegiando os grupos de alunos para os quais a escola é uma das únicas fontes de conhecimento sistematizado, ao não
oferecer-Ihes condições adequadas de aprendizagem. Qual seria o verdadeiro papel desse sistema escolar: excluir os potencialmente excluídos?

À guisa de conclusão, vale destacar que, sem maiores investimentos no desenvolvimento de indicadores educacionais que informem efetivamente sobre as políticas vigentes, bem como sobre as práticas atuais em salas de aula, dificilmente será possível a definição de objetivos adequados, viáveis e, sobretudo, socialmente significativos, considerando os diversos sistemas educacionais, em seus diferentes níveis, voltados para preparação de nossas crianças e jovens para sobreviver e competir com padrões mínimos de igualdade na sociedade atual.

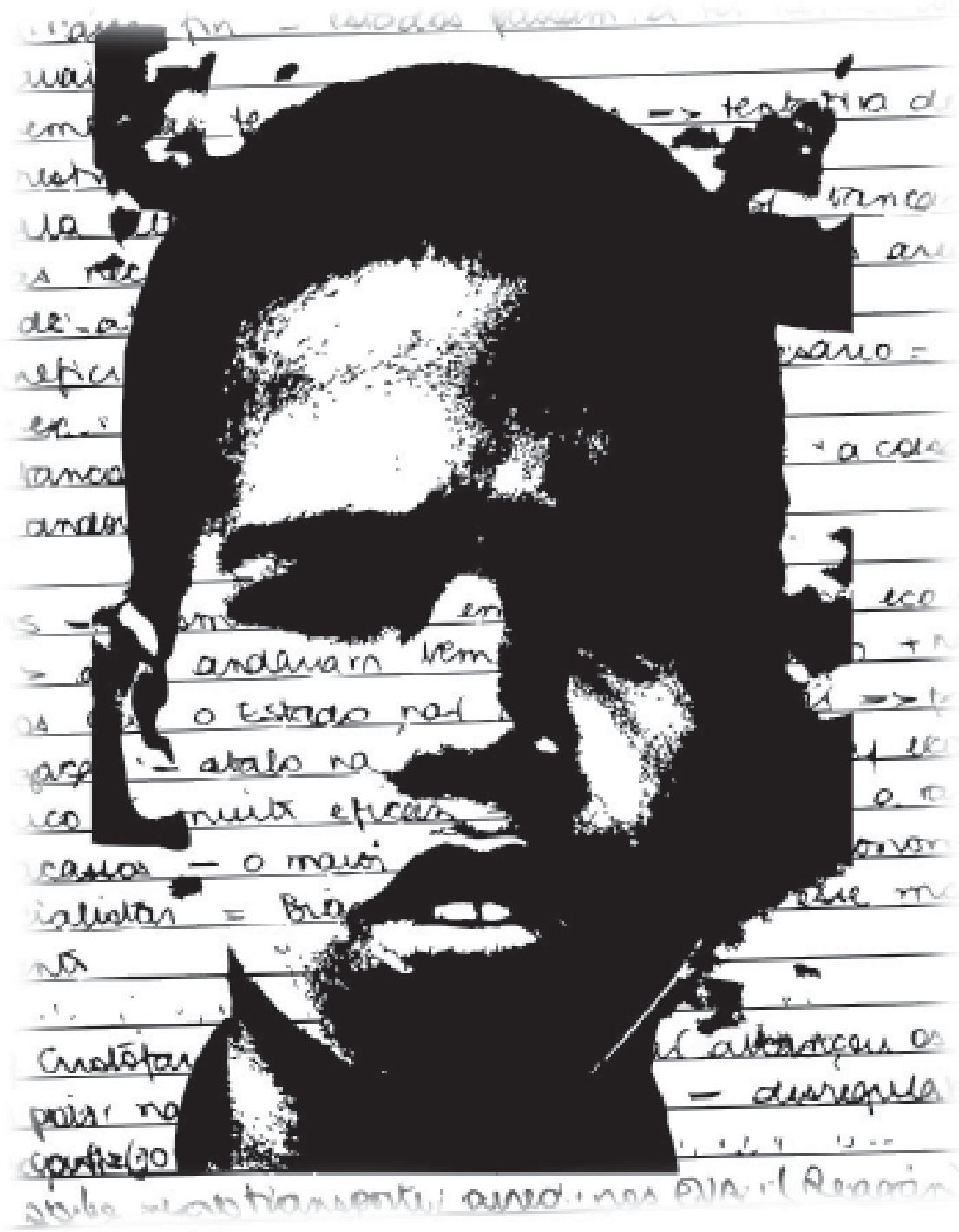




\section{Referências bibliográficas}

BOTTANI, N. E., TUIJNMAN, A. International education indicators : framework, development and interpretation. In: ORGANISATION FOR ECONOMIC CO-OPERATION AND DEVELOPMENT. Making education count. Paris : OECD, 1994. p. 21-35.

DARLING-HAMMOND, L., ASCHER, C. Accountability mechanism in big city school system [online]. Eric Digest, n. 71, 1991. Disponível na Internet: <http://ericae.net/>

FRANCO, M. L. P. B. Qualidade de ensino : critérios e avaliação de seus indicadores. São Paulo : FDE, 1994. p. 81-87. (Série Idéias, 22)

MAINARDES, J. A promoção automática em questão : argumentos, implicações e possibilidades. Revista Brasileira de Estudos Pedagógicos, Brasília, v. 79, n. 192, p. 16-29, maio/ago. 1998.

NUTTALL, D. Choosing indicators. In: ORGANISATION FOR ECONOMIC CO-OPERATION AND DEVELOPMENT. Making education count. Paris : OECD, 1994. p. 79-96.

PERFIL socioeducacional das escolas paulistas [online]. São Paulo : Seade/IBGE, 1999.

REALI, Aline M. M. R. Diagnóstico da rede de ensino pré-escolar, de $1^{\circ}$ e $2^{\circ}$ graus localizada do município de São Carlos-SP : caracterização do corpo discente. São Carlos : UFSCar, 1997. 204 p. Relatório de pesquisa.

SÃO PAULO. Secretaria Estadual da Educação. Reorganização das escolas da rede pública estadual. São Paulo, 1995.

Reorganização : deu certo! Escola Agora, v. 2, n. 11, p. 1, maio 1997a. Ed. Especial.

Resultados do Projeto Escola nas Férias. São Paulo, 1997b.

SHAVELSON, R. J. et al. What are educational indicators and indicators systems? [online]. Eric Digest, n. ED338701, 1991. Disponível na Internet: <http://www.edrs.com/ ED33870>.

Recebido em 3 de maio de 2000.

Aline Maria de Medeiros Rodrigues Reali, doutora em Psicologia Experimental pelo Instituto de Psicologia da Universidade de São Paulo (USP), é professora adjunta do Departamento de Metodologia de Ensino do Centro de Educação e Ciências Humanas (CECH) da Universidade Federal de São Carlos (UFSCar).

Vicente Manuel Cristofoletti Calvo é mestrando do Programa de Pós-Graduação do $\mathrm{CECH} / \mathrm{UFSCar}$.

\section{Abstract}

The present work describes a comparative analysis about the public state educational system in a municipalityof the state of São Paulo in different moments: before (1994) and after (1996) the "reorganization" of the school system. It was considered as data source the Levantamento de Dados Escolares (LDE) which contains information about the numbers of registered students and classes, average number of students per class, promotions, failure and dropouts considering the different school sectors and levels of teaching of the state educational system. The comparison of the two years data, or the educational indicators, showed differences concerning the introduction of the new educational politics and questions and hypothesis related to the better comprehension of the consequences of their implementation.

Keywords: educational indicators; evaluation of educational systems; student body; public politics. 